\title{
Clearing the Muddled Path of Traditional and Contemporary Mindfulness: a Response to Monteiro, Musten, and Compson
}

\author{
Ronald E. Purser
}

Published online: 25 December 2014

(C) Springer Science+Business Media New York 2014

\section{Introduction}

In their article, Monteiro, Musten and Compson (2015) explored the criticisms regarding the proliferation of contemporary mindfulness programs by attempting to represent the positions and concerns of the traditional Buddhist community. They noted that traditional Buddhists have raised alarms over the proliferation of mindfulness programs primarily because such contemporary applications have significantly diverged from canonical definitions of mindfulness as derived from the vast corpus of traditional Buddhist texts and practices. In addition, they characterized such objections by traditional Buddhists as a groundswell of protest, particularly when concerns are raised over the absence of ethics, or sila, in clinical and nonclinical mindfulness programs. They also touch on issues pertaining to a clash of worldviews between religion and science, as well as the teaching of secular mindfulness programs in corporations and the military.

Monteiro et al. (2015) framed the debate, first in terms of two streams, the traditional Buddhist community (which is depicted as fiercely critical of the other stream) - namely, contemporary mindfulness, as propagated and practiced by secular and clinical mindfulness practitioners. This framing has some merit, as the concerns raised have been the subject of much debate and attention in both the popular press and Buddhist blogosphere, such as Purser and Loy's (2013) "Beyond McMindfulness," North's (2014) op-ed piece "The Mindfulness Backlash" in the New York Times, Thompson (2014), "The Mindfulness Wars," Whitaker's (2013) “2013 as the year of mindfulness: Critics and defenders," and Roca's

R. E. Purser $(\bowtie)$

College of Business, Bus 349, San Francisco State University, 1600

Holloway Avenue, San Francisco, CA 94132, USA

e-mail: rpurser@sfsu.edu
(2014) "The Dark Night of the Soul." In addition, numerous Buddhist teachers and religious studies scholars have weighed in on the medicalization and psychologization of mindfulness, considering how such reinterpretations alter the meaning, function and ends of such secular practices (Bazzano 2013; Brazier 2013; Buswell and Lopez 2014; Cohen 2010; Lopez 2012; Samuel 2014; Stanley 2013; Thanissaro 2012; Wallace 2007). In addition to analyzing and describing the trend towards the decontextualization of mindfulness and the role it plays within an integrated Buddhist path of liberation, a number of scholars have also described, perhaps more importantly, how contemporary mindfulness applications have undergone a refashioning and make over in order to accommodate the needs of Western society deeply rooted in individualism, consumer capitalism, along with its pragmatic demands for tangible and worldly benefits (McMahan 2008; Schedneck 2013; Stanley 2013; Wilson 2014).

Monteiro et al. have emphasized two extreme views by narrowly framing the debate simply in terms of definitional squabbles of what constitutes right mindfulness and the absence of an explicit ethical framework for mindfulness-based interventions (MBIs). Bhikkhu Bodhi (2014a) has chronicled this polar opposition in what he calls a "fusion of horizons." On one side of the polarity are the conservative Buddhists, who believe the Dharma must be kept pure, that it should be preserved and protected, and that introducing any changes is simply a slippery slope to an eventual degradation and wholesale dilution of the Buddhist teachings. On the other end of the spectrum are the contemporary mindfulness advocates, who believe that Buddhism has always evolved as it migrates to new cultures, and that the West is not any different. Therefore, the Dharma is mutable and should be adaptive and relevant to modern times by shedding its religious overtones, superstitions, and cultural baggage. Contemporary mindfulness is pragmatic and therapeutic - its aim is to reduce suffering in the here and now. The slogan, "meeting people where they are 
at," is the mantra for contemporary mindfulness advocates. While there is some degree of validity to these characterizations, this extremist comparison, which Monteiro et al. focus on as being representative of the "tangle of concerns," often depicts Buddhist traditionalists as inflexible, dogmatic, and deficiently adaptive, in effect, setting up traditional Buddhism as a straw man. This is curious, given that the Bhikkhu Bodhi (2011, pp. 35-36), an American monk and one of the key voices for "traditional Buddhism" in the West, has remarked that:

“...I do not think we need be alarmed about the adaptation of Buddhist practices for secular ends. I call to mind a statement the Buddha made in the weeks before his death: 'The Tathagata has no closed fist of a teacher with respect to teachings.' By this he meant that he had taught everything important without holding back any esoteric doctrines, but I like to interpret his words to mean that we can let anyone take from the Dhamma whatever they find useful even if it is for secular purposes."

In their characterization of "a growing and sometimesfraught debate" between traditional and contemporary mindfulness, Monteiro et al. (2015) apparently have chosen to omit the equally numerous criticisms and defensive retorts coming from contemporary mindfulness advocates (Goldstein 2013; Halliwell 2011; Hunter 2013; Nicklebine 2013; Segal 2013), which have not been exactly congenial to the traditional Buddhist community. More importantly, this narrow framing of the issues serves to deflect attention away from the "mystification" of mindfulness, a term Wilson (2014) has recently used to describe the intentional rhetorical tactics and processes involved in extracting and uprooting mindfulness from its grounding in a religious tradition, informed not only on a foundation of morality and ethics, but which is motivated by soteriological aims for the cessation of $d u k k h a$, liberation from samsara, and a compassionate commitment to act for the welfare of all sentient beings. It is this process of mystification that also accounts for the widespread misconception in the West that Buddhist practice is synonymous with mindfulness meditation. Such cultural appropriation was of course the outgrowth of the mainstreaming mindfulness for clinical and non-Buddhist populations, a movement that has now come to permeate the mass media with its appeal as a convenient remedy for the everyday stresses and anxieties of the Western consumer.

\section{Mixed Messages of Contemporary Mindfulness}

Another problem in this categorization scheme is that while contemporary mindfulness is defined as "all forms of mindfulness programs that are not explicitly based in Buddhist practice" (Monteiro et al. 2015, p. 1), the most established, popular, and researched clinical program, mindfulness-based stress reduction (MBSR), now advertises its training and curriculum "as a vehicle for embodying and transmitting the dharma in a wholly secular and universal idiom. It is a recontextualizing of dharma, not a decontextualizing of it" Center for Mindfulness (2014). Williams and Kabat-Zinn (2011, p. 15) have even gone so far to say that MBSR and MBIs are a recontextualization of the Buddhist teachings in all of their "essential fullness.". In fact, the preface statement to the standards and principles expected of a MBSR teacher explicitly makes mention of the fact that MBSR derives much of its approach from Buddhist practices, underscoring that mindfulness is "the heart of Buddhist meditation." Prospective MBSR teachers are expected "to be a committed student of the dharma, as it is expressed both within the Buddhist meditation traditions and in more mainstream and universal contexts exemplified by MBSR" (Center for Mindfulness 2014). This strong requirement - to be committed to the dharma, with an explicit emphasis on Buddhist meditation-is qualified, however, by a curious exemption clause: "This has nothing to do with being or not being a Buddhist" (Center for Mindfulness 2014).

How should one make sense of these mystifying statements? It appears that MBSR teacher training is indeed explicitly based in Buddhist meditative practice and in a Buddhist context; its teachers are expected to be committed to the "dharma" and undertake long, 7-10-day silent retreats, preferably in the Western Buddhist vipassana tradition. At a meeting of MBSR teachers in Northern California, Saki Santorelli, the Executive Director for the Center for Mindfulness, emphasized the need for more in-depth teacher training and declared that the Center for Mindfulness (CFM) is in the business of training dharma teachers. And a senior MBSR teacher-trainer at the CFM has adamantly stated, "I really feel MBSR is not secular ..." and that "MBSR is very spiritual and holy. If you look inside the curriculum you will find it is inspired from the essence and heart of the Dhamma." Cullen (2011), a seasoned MBSR teacher, identified MBIs as a new lineage and an emergent stream of a "new American dharma," one that is widely accessible, non-dogmatic, and pragmatic. Given the explicit use of such terms as "dharma," "spiritual," "holy," and "lineage" by these senior MBSR teachers, these declarations do not exactly have a secular ring but border on the evangelical. Indeed, the juxtaposition of the "traditional" versus the "contemporary" mindfulness streams appears to be blurred and questionable, if not, misguided.

It is understandable, however, why Monteiro et al. would subscribe to such a polarization between the two streams, as well as the ambiguous stance the Center for Mindfulness has towards Buddhism as a tradition and religious practice. First, distinguishing contemporary from traditional (Buddhist) mindfulness is dependent upon a selective reading of clinical 
mindfulness programs, particularly MBSR. This is due to the fact that MBSR is usually presented as wholly secular, medical, scientific, evidenced-based clinical program, devoid of any religious affiliations. And this emphasis on the secular and scientific is certainly the case when mindfulness-based programs are targeted for implementation in public schools, or in seeking grant funding from federal agencies such as National Institute of Health (NIH) and the Department of Defense (DoD). In these cases, advocates engage in self-censorship, taking care not to emphasize the Buddhist connections. In other words, depending on the recipient, MBSR is billed, on the one hand, as an either wholly secular and contemporary program, or on the other hand, as a sacred, spiritual, and holy practice - a faithful recontextualization of the dharma. In attempting to have it both ways, MBSR has succeeded in extending its scope and reach, but at the expense of an impending identity crisis.

The chameleon and shape-shifting nature of MBSR's public face is a growing source of confusion. Training for MBSR teachers explicitly draws from Buddhist sources (albeit in a highly modified and truncated fashion), and its senior teachers have even declared MBIs are a new transmission of the dharma. Many Western Buddhist centers (mostly Western Insight Meditation and some progressive Zen centers) even offer MBSR courses alongside traditional Buddhist classes. Kabat-Zinn (2011, p. 12) has even referred to MBSR and other related MBIs as "Dharma based portals." Despite this intermingling, there is still an intentional distancing from Buddhism as a faith tradition, which should come as no surprise, since in a secular society, many consider religious traditions to be suspect - the legacy of outdated, corrupt, and authoritarian premodern institutions.

CFM's qualifying statement that MBSR teacher training, "...has nothing to do with being or not being a Buddhist" (Center for Mindfulness 2014) can also be seen even within Western Buddhism. Because Monteiro et al. have focused on the extreme end of a spectrum that they label as traditional Buddhism, they failed to consider the middle ground of contemporary Western Buddhism - which has already distanced itself from religious Buddhism. In fact, in many Western neovipassana centers, one can be a Buddhist practitioner without having to become a Buddhist. The taking of Buddhist vows in the Buddha, Dharma, and Sangha (the traditional ceremony of Buddhist conversion) is generally not offered in such centers nor on meditation retreats, and the taking of Buddhist ethical precepts is usually limited to while one is on a retreat, rather than as a commitment to the whole of one's life.

Therefore, it is quite obvious that by promoting mindfulness as non-religious, intentionally decoupling it from Buddhism, the contemporary mindfulness community has been able to offer mindfulness practice to a much wider population. However, within the MBSR/MBI teacher communities, Buddhist teachings and practices are explicitly recognized as a resource for their curricula and ongoing training. Buddhism as a faith tradition and religion is downplayed, replaced by Buddhist modernism's image of the Buddha as a scientist and radical empiricist, and the teachings, the practices, and mindfulness meditation as the expression of a "universal dharma." Wilson (2014, p. 161) makes a very astute observation regarding this strategy:

“...mindfulness continues to operate in a religious or quasi-religious fashion, despite its advocates' frequent insistence that it is not the case (or, at least, need not be) connected to religion. As we've seen, religion and values are downplayed by mindfulness authors to garner large audiences - but in many cases, the reason they want an audience in the first place is because they are convinced that mindfulness and other elements derived from Buddhism have a real ability to alleviate suffering (the goal of religious Buddhism)....Mindfulness is connected to a whole set of self-disciplinary and lifestyle practices that are given moral weight by their promoters. Even if we accept the protestations of many advocates that mindfulness is not a religion per se, it is nonetheless doing the work of religions."

This blurring of boundaries between the so-called contemporary-traditional mindfulness communities, along with the incongruence in messaging (MBIs as sacred, new transmission of the dharma, grounded in Buddhist teachings vs. wholly secular, evidenced-based, scientific, clinical interventions), is not only creating a great deal of confusion but also ethical and credibility issues (Shonin, Van Gordon and Griffiths 2013). As Shonin et al. (2013, p. 2) pointed out:

“...such spiritually-laden language appears to be incongruent with the general presentation and conceptualization of MBIs in relation to their operationalization within clinical settings. Thus, the identity of MBIs as well as their primary underlying "intention" (i.e., a means of improving psychosomatic well-being or a tool for spiritual development) appears to be slightly confused, and this is potentially confusing for service-users."

Contemporary mindfulness teachers are fond of saying that traditional Buddhists "don't own mindfulness" (Goldstein 2013) or as Monteiro et al. (2015, p. 7) noted, "whether Buddhism has sole propriety rights to the concept of mindfulness and its dissemination." However, the dispute here, as Shonin et al. (2013) showed, is not one of intellectual property but of truth in advertising. Traditional Buddhists, as Bhikkhu Bodhi's earlier statement revealed, have no issue with the adaptation of mindfulness for secular and clinical purposes, which aims at symptom reduction and improvements in psychosomatic well-being. However, if service users, especially those in healthcare settings, are really being taught a form of 
"stealth Buddhism," that's an ethical issue. Trying to have it both ways is both problematic and disingenuous. At McGill University's Advanced Study Institute, Mindfulness in Cultural Context conference, Thupten Jinpa Langri (2013), the Dalai Lama's long-time translator and interpreter agreed:

"Although, I am aware that sometimes, the presenters of mindfulness practices on the one hand, want to argue this [mindfulness] has nothing to do with Buddhism, it is secular...but at the same time, they want to argue this is the essence of the Buddhist teachings. I've often told them, you know, you cannot have it both ways. It is either secular, or you want to say its the essence of Buddhism, therefore it's a Buddhist practice. You cannot have it both ways."

This phenomenon of "dual identities" may have legal implications in terms of an evasion of professional accountability and a potential violation of informed consent laws. As Brown (2013) pointed out, there is a growing controversy that Complementary Alternative Medicine (CAM) providers may not be meeting the reasonable-person standard providing service users (clients) the information necessary to make informed decisions. Because both MBSR and MBIs can be considered forms of CAM, providing only information limited to medical risks is insufficient. Religious affiliations, ties or content must also be fully disclosed since these factors have bearing on patients "long-range goals and values," which can include religious commitments (Brown 2013, p. 201). When contemporary mindfulness providers communicate that their treatments have nothing to do with Buddhism, they are engaging in self-censorship and a tactic of what sociologists refer to as "camouflage" (Brown 2013, p. 209). Brown (2013, p. 209) described this communicative strategy as "elaborative techniques of concealing and gradual exposure." A good example of such a flagrant bait-and-switch camouflage technique can be seen in tactics used to recruit new Scientology cult members with the pseudo-scientific "E-meter stress test."

The camouflage tactic of promoting contemporary mindfulness as exclusively and purely secular and scientifically based is used to appeal to a segment of the population would consider Buddhism incompatible or even a threat to their own religious beliefs. This failure of full disclosure may fall short of meeting the standards of informed consent, which legally and ethically requires whether such a treatment may, according to attorney Richard Steinecke, "offend a religious, ethical or personal belief of the patient" (Brown 2013, p. 208). According to the reasonable-person standard of informed consent, protecting patient rights requires respecting the personal autonomy of patients to make their own decisions and, in order to do so, they must have access to the necessary information that is material to their decision making. Drawing from the work of ethicist Beauchamp (2010), Brown (2013, p.
201) reiterated his main premise that "patients cannot intentionally participate in CAM without understanding the consequences of their actions for both health and religion."

Brown (2013) went on to describe how spiritual teachers and trainers first seek to gain the trust of their clients by utilizing more neutral language, gradually introducing more spiritually laden concepts and practices:

"Jon Kabat-Zinn minimizes spiritual vocabulary during his eight-week mindfulness-based stress reduction classes. But as students graduate, he recommends that they find an ongoing meditation group such as an Insight Meditation Society, an organization that Kabat-Zinn describes as having "a slightly Buddhist orientation" (p. 209).

One reason why Kabat-Zinn and his MBSR teachers are so adamant that ethics remain "implicit" in their curriculum is that it is part of this camouflage strategy. In order to cast the widest possible net and "mainstream" mindfulness, an explicit commitment to ethics and or any appearance of religious affiliations with Buddhism would compromise that strategy. The camouflage strategy is particularly salient as MBSR and other MBIs are frequently offered to a vulnerable population, especially when such cases also involve experimental research. Brown (2013) argued that in such instances "therapeutic misconception" may be occurring, whereas the patients who are consenting to such mindfulness treatments believe they are receiving medically and scientifically based therapies, when in reality they are gradually be introduced to religious practices, without full disclosure or informed consent. Even if such disclosure was forthcoming, Shonin et al. (2013 p. 3) also pointed out the claims that MBIs are "grounded" in the Buddhist teachings, or other such language as being "inspired" or "informed" by Buddhism, need to be honest and forthright in that such adaptations are "by no means congruent with the traditional Buddhist perspective." Up until now, MBSR and MBIs have maintained that the ethical dimension of their treatment is covered already by professional standards (such as the Hippocratic Oath), especially if such service providers are licensed psychotherapists or health service providers. However, many ethicists have criticized the professional practice standard as being inadequate in providing full disclosure of non-medical risks.

\section{Questioning the Buddhist Roots of Contemporary Mindfulness}

Monteiro et al. devoted a considerable amount of time expounding on the function and purpose of the Eightfold Path as a means for understanding behaviors and attitudes that are skillful and wholesome, as well as for contextualizing and 
defining right mindfulness (sammā sati). They went on to make the claim that Eightfold Path could best be understood not only as a set of guidelines for the development of skillful conduct, meditative concentration, and wisdom but also as an universal cosmic law of nature. They claimed that the Eightfold Path is actually a causal law of nature, "not an invention of the Buddha or any other teacher, any more than gravity, for example, was the invention of Newton" (Monteiro et al. 2015). While their source for this claim is derived from (Gethin 2001, p. 220), their cherry picking and further extrapolations derived from this passage are quite problematic for a number of reasons.

First, Gethin (2001, p. 225) later clarified (in the same chapter that Monteiro et al. referenced) that the Noble Eightfold Path (ariyo atthangiko maggo) "was always primarily conceived of as a way of practicing or of going along ..." and that the eight factors of the path have always been "thought of as eight items that are to be collectively brought to rightness." Gethin went on to point out that in the early stages of the path, the aspirant learns to abandon wrong views, which is still at the level of "ordinary right view." At this stage, the aspirant still has many doubts as to whether the path will ultimately lead to the cessation of suffering. It is not until the aspirant develops supermundane right view, which is considered noble, that the aspirant dispels all doubt, knowing with full confidence that the path truly does deliver on its promise. Such a conversion experience is also known in the Pali literature as becoming a "stream-enterer" (sotāpanna), which is actually characterized, according to Gethin (2001, p. 225) "as one who has complete trust (avecca-ppasada) in the Buddha, Dharma, and Sangha, as one who has overcome doubt." Clearly, developing complete trust in the three jewels implies a direct knowledge of, and deep commitment to, the Buddhist teachings. Monteiro et al.'s (2015, p. 3) assertion “...but there is no reason in principle why familiarity with explicitly 'Buddhist' teachings are a necessary condition for such liberation" is in direct contradiction to Gethin's account of the streamenterer on the path to liberation is one who develops "has complete trust in the Buddha, Dharma, and Sangha."

Second, the comparison of the Eightfold Path as a universal and causal law of nature, not unlike that of gravity, is a faulty analogy. Surely, the natural laws of gravity existed prior to Newton's formulations, but the premise that the specifics of the eight-path factors are eternal, universal, and cosmic laws operating on human beings in a similar fashion as gravity causes apples to fall from a tree is to commit a category error. There are similar tropes often trotted out by the contemporary mindfulness community, such as we need not become believers in Islam in order to use algebra, or become converts to Hinduism in order to use subtraction, or that there is no such thing as a Christian physics. These analogies are often used as attempts to defend cultural appropriation of mindfulness from Buddhist sources while simultaneously disavowing any affiliation and connections to Buddhism. The reason such analogies are faulty is because science and its natural laws are not a cultural enterprise (Coseru 2014). Cultural artifacts, in this case, the formulation of the Noble Eightfold Path by the Buddha, is not amenable to, nor can be reduced to, scientific explanation. Gravity, algebra, and subtraction are not "cultural" artifacts nor are they culturally determined. As Coseru (2014, p. 1) pointed out, "the principles of mathematics [or laws of gravity] apply regardless of religious beliefs or cultural norms" and that there is a world of difference between the domains of scientific inquiry and culturally determined human values and endeavors. Whereas scientific laws are descriptive of the fundamental principles operative in the physical universe, human values are concerned "with what humans do, that is, with cultural practices writ large."

The Eightfold Path is both a religious and cultural practice that exists in a completely different domain than gravity, physics and mathematics. As Coseru (2014, p. 1) explained, in cultural domains we cannot make claims that:

"Beethoven's 9th symphony is not truer than Mozart's, Jazz is not truer than classical music, and mindfulness meditation is not truer than contemplative prayer because truth is not their currency, at least not scientific truth. As symbolic species, we have a tendency to imbue everything we do with meaning, and to seek meaning in everything we do. That is why we have social and cultural institutions. I don't mean to suggest that scientific inquiries and the kind of inquiries we pursue in the humanities and the social sciences should be kept apart, just that phenomena that fall under one description are not amenable to descriptions in other domains."

Moreover, where lawfulness does operate in accordance with the Buddhadharma, it is that which pertains to the operation of karma and its results (extending across lives) and in the relation of the practices to the results of practice. But properly, these are matters that are described as paccatta veditabbo viñ̃ühi - "to be realized personally by the wise" (Bodhi 2014c). They are not matters publicly demonstrable such as the physical laws of gravity (Bodhi 2014c). By making an appeal to universality, Monteiro et al. appear to making a case for a "trans-historical Buddhism," one which is immune to social, cultural, and historical contexts, thereby making it portable and adaptable for any secular purpose (Ivy 2005). Their claim that the "outcome of the training transcends Buddhist teachings" is not new (Monteiro et al. 2015, p. 3); in fact, it can be traced directly to Kabat-Zinn (2011) assertions that the "dharma" is analogous to the fundamental physical laws of the universe, coupled with the claim that MBSR is the essence of a "universal dharma."

For example, Kabat-Zinn (2011b, p. 57) exclaimed, "The word Dharma refers to both the teachings of the Buddha and 
also the way things are, the fundamental lawfulness of the universe. So although the Buddha articulated the Dharma, the Dharma itself cannot be Buddhist any more than the law of gravity is English because of Newton or Italian because of Galileo. It is a universal lawfulness." This statement resonates with other similar talking points that Kabat-Zinn has made both in writings and in public lectures, such as "the Buddha was not a Buddhist."

A more telling remark is the one Kabat-Zinn (2013) made at the New York Academy of Sciences, in response to a question asked by the moderator as to whether mindfulness was really an offshoot of Buddhism:

“The Buddha wasn't a Buddhist....we turn the Buddha into some big thing. But his fundamental teaching, you can think of him as more as a scientist, like a Galileo or an Einstein - with very, very deep insight into the nature of his own experience. But from the point of view of mindfulness, and although it is spoken of as the heart of Buddhist meditation, it's about paying attention. How Buddhist is that? It's about awareness, how Buddhist is that? It's about loving-kindness, how Buddhist is that? Or compassion? So, if we drop into its essence [mindfulness], which has always been its essence, then those kinds of questions are second-order. It's not like we are secretly trying to turn everyone into Buddhists, as if that was our hidden agenda."

In the above public statements, it is apparent that KabatZinn distances mindfulness from its Buddhist roots, arguing that the mental states and qualities resulting from the practice of mindfulness meditation - such as paying attention, awareness, loving-kindness, and compassion - are not exclusive to the Buddhist domain. This rhetorical strategy tracks with Wilson's (2014) analysis of how the cultural appropriation of mindfulness is a progressive, multi-stage process. As Wilson pointed out, first Buddhism was made more palatable by singling out mindfulness as the heart of Buddhism, making Buddhism itself more marketable to the West. The next stage involves purging Buddhism and any overt associations to Buddhism in order to promote and sell mindfulness.

This purging of Buddhism in order to promote secular mindfulness has rested squarely on the way the term "Dharma" has been appropriated by Kabat-Zinn. Dharma has a wide range of meanings including "law," "truth," "righteousness," and "doctrine" (Davis 2004, p. 21). However, as Davis (2004, p. 22) pointed out, the decision to appropriate this term as a stand alone essence of the Buddhist teachings, as well as strategic means for purging its association with the Buddhist path, reduces its meaning to mainly its philosophical and psychological aspects. In fact, Davis argued that this rhetorical move negates and discounts a crucial aspect of how the dhamma was conceived and taught in many of the Buddha's discourses, which emphasized the application of the Dhamma-Vinaya - which "refer specifically to the restraint of a person's unskillful mental and physical activity, and the cultivation of skillful mental and activity, for the purpose of developing insight and thus gaining total liberation from suffering" (Davis 2004, p. 22). There are a number of passages in the Pali Tipitaka where the Buddha makes it very clear that he taught the "Dhamma and Discipline proclaimed by the Tathagata" (Bodhi 2014a).

In a special issue of Contemporary Buddhism, (Kabat-Zinn 2011, p. 290) stated that MBSR is the "universal dharma that is co-extensive, if not identical, with the teachings of the Buddha, the Buddhadharma." At first glance, Kabat-Zinn's bold assertion may seem contradictory to Wilson's observation that the purging and elimination of Buddhism is a strategic step towards the propagation of a secular and contemporary form of mindfulness. Kabat-Zinn, however, has been very clear and open in previous writings that chronicle his long history of Buddhist training at Western Insight Meditation centers and in Korean Zen. Nevertheless, it is curious as to why Kabat-Zinn gestures to the teachings of the Buddha and the Buddhadharma when in many of his other writings and public talks he goes out of his way to distance MBSR from Buddhism. While some may view his claim as overstating the case, or even grandiose, such a statement lends a certain cache in the branding of MBSR for the spiritual but not religious population. However, claiming MBSR is co-extensive with the Buddhadharma does call into question the entire premise of Monteiro et al.'s (2015) "contemporary-traditional" mindfulness dichotomy. If MBSR "is co-extensive, if not identical to teachings of the Buddha," it certainly appears to sound as if it is explicitly based in Buddhist practice, which, according to Monteiro et al.'s (2015) definition, would place it back into the traditional category. More importantly, this statement reveals a major assumption that Buddhism itself has a universal essence that can be extracted and repackaged for mass secular consumption. In this case, the essence is, of course, mindfulness as its conceived and refashioned by Kabat-Zinn and therefore it is not really Buddhism that we are interested in, but the dharma. Analyzing Kabat-Zinn's various rhetorical strategies, Wilson (2014, p. 89) summed up his observations:

"Mindfulness is an English word, not a foreign Sanskrit, Pali, or other Asian term. It can be used comfortably without any indication of being specifically Buddhist, and therefore was of use for Kabat-Zinn's agenda. At the same time, he intended mindfulness to mean not only awareness and meditation but also a shorthand for the Buddhist tradition, so that Buddhism could be brought into non-Buddhist settings by simply substituting a different word that would not set off alarm bells. Arguably, then, when Kabat-Zinn speaks of mindfulness-based stress reduction he in fact means Buddhist-Based (or at 
least Dharma-Based) Stress Reduction, given this intended double definition of mindfulness" (italics in original).

At the Buddhism in America conference, Kabat-Zinn explained his view: "The Dharma, to me, is pointing to something that really is universal ... The cultural and ideological overlays, and the historical elements of [Buddhism], beautiful and honorable and wonderful as they are, are not necessarily the heart of the Dharma, which transcends them." However, the premise that the "Dharma" can be extracted from the Buddhadharma, and essentialized, is equivalent to closed system thinking (Wilden 1980). No system, especially the teachings of the Dharma, is ever totally closed, or ever totally independent. Moreover, the notion of a universal "essence" actually contradicts one of the core Buddhist teachings of noself nature, or annattā, for an essence assumes the characteristic of a "thing" independent of interactions, relationships and a social-historical context. In many respects, Kabat-Zinn (2011) and Monteiro et al. (2015) fall prey to the belief that contemporary mindfulness is a universal, "noncultural" form of Buddhism, reflective of a collective blind spot among North Americans to downplay the importance of culture. Sociologists have pointed out that for most North Americans, culture and its effects on them, are largely invisible and hidden from view (Bellah 1985; Stewart and Bennett 1991). This tendency to downplay or minimize the cultural dimension shows up in the contemporary mindfulness movement's celebration of personal freedom, authenticity, and the emphasis on the primacy of the individual as the sole moral agent and source of authority.

The cross-cultural research compiled by Stewart and Bennett (1991) sheds light on the cultural influences on the mindfulness movement in North America. Their broad generalizations show that North Americans' self-concept is one of a highly individualistic and atomized unit in society, with little commitment to community or tradition. North Americans are also a highly pragmatic culture and tend to reject historical, sociological, and philosophical principles, preferring psychological theories. In this respect, North Americans have a naïve view that they have an immunity to cultural influences and demonstrate a pronounced ethnocentricism and fear of that which is foreign and alien. Wilson's (2014, p. 131) concluding remarks regarding this peculiar North Americanization of the mindfulness movement is worth considering at length:

"One possible irony of the mindfulness movement is that it emerged in part from movements that desired to reform Buddhism and get back to its original, authentic teachings of the historical Buddha. Many early Western authors espouse a radically modified form of Buddhism pruned of what they call "Asian trappings" that were accumulated by supposedly "impure mixtures" of basic
Buddhism with local cultural traditions and outside religions, such as Confucianism or animistic cults. ....Yet, this newly pared-down Buddhism that supposedly returns to Indian roots is eminently prepared to be applied to the worldly cultural concerns of Americans, especially those in the middle-class, mainly white communities that have dominated the public conversation over what American Buddhism should be. .... Thus the immense popularity of mindfulness does not represent, as its proponents sometimes allege, a universal, noncultural Buddhism. Instead, the application of mindfulness to so many aspects of American culture is in fact clearly yet another "practical benefits" approach to Buddhism, pursued in this case by American Buddhists and sympathizers. Though some believe they have done away with "attachment-based" utilizations of Buddhism, in fact their stripped-down approach makes aspects of Buddhism available for attachment to new culturespecific concerns such as overeating, wasteful consumption, parenting difficulties, and workplace stress-so available, in fact, that many of the people developing such applications are not Buddhists themselves."

In tracing the development of the contemporary understanding of mindfulness, Monteiro et al. (2015) turn to Sharf's (2013) critique of "Buddhist modernism," linking the therapeutic turn in mindfulness to the Theravada revival movement of the early twentieth century. Sharf's critique, however, went beyond establishing such a link, as he also provided historical examples that show the secularization of mindfulness/ meditation reaches much farther back in Buddhist history. For example, Sharf traced the notions of "bare attention" and "present-centered awareness" to other historical instances besides the Theravada reform movements, particularly the popularization of Chan meditation in eighth-century China. In this latter case, Sharf noted that some Zen (Chan) sects promoted a method of meditation to the laity - a method that emphasized dwelling within present moment experience with promises of a fast-track to liberation. However, a number of Zen reformers, such as Dahui, were vehemently critical of this method of "present-centered awareness," and considered it to be a form of "meditation sickness," whereby the meditator becomes passively content with quiescence, losing interest in and responsiveness to the suffering of the world. Sharf's critique revealed that even in the Buddhist world, mindfulness meditation has been decontextualized and stripped of its moral and philosophical theories, and that such critiques have been commonplace among Buddhists reformers for at least a millennia.

There are also a number of historical inaccuracies regarding the Theravada reform movement that are in need of correction. While Mahasi Sayadaw is often attributed to be the forerunner of the Theravada vispassana reform movement, 
his role was paved by many prominent Burmese monks before him, such as the notable Ledi Sayadaw (Braun 2013). Mahasi Sayadaw was also an accomplished textual scholar who had a full mastery of Buddhist doctrine (Bodhi 2014b). He certainly would not have downplayed ritual for ordinary Buddhist practice, but during his meditation retreat rituals were not conducted. Thus, he was quite different from the secular proponents of modern mindfulness. Even S.N. Goenka, who might also be considered a "Buddhist modernist," actually incorporated ritual into his meditation courses, with chanting and his invocation of the blessings of the "Bodhi Dhatu, Nirvana Dhatu" upon the meditators at the beginning of each day's practice. Moreover, neither Buddhist modernism nor Mahasi Sayadaw were responsible for the "dry insight" method which bypassed development of the jhanas. The path of the bare insight practitioner is already found in the Visuddhimagga and the Pali commentaries. For intensive meditation practice in any tradition, intricate doctrinal instruction may not be not given, but an accomplished Buddhist teacher will guide the students on the basis of his own knowledge of doctrine through the stages of development. In the case of the Mahasi method, bare mindfulness of the present is the starting point of the practice, but with the progress of the practice the student is guided into the stages of insight according to the classical model laid out in texts like the Pațisambhidāmagga and the Visuddhimagga (Bodhi 2014b). Contrary to Monteiro et al.'s (2015) claim that the Theravada reform movement required no familiarity with Buddhist philosophy or traditional commentarial texts such as the Abhidhamma, one the foremost pioneers and leaders of this movement, Ledi Sayadaw, was a strong advocate for systematic study, textual learning, particularly the Abhidhamma, on the part of the laity (Braun 2013). While it is true that both Mahasi Sayadaw and Ledi Sayadaw downplayed the cultivation of concentration (samādhi), they stressed meditation as a practice depended on textual learning. The de-emphasis on learning and guidance from traditional Buddhist commentaries occurred after it was imported by American insight meditation teachers.

\section{Cultivation of Therapeutic Well-Being vs. a Transformative Vision of Moral Engagement}

The description and function which Monteiro et al. (2015) provided of contemporary mindfulness-based interventions is essentially therapeutic, with an overall focus on the cultivation of individual well-being. They presented a components model of mindfulness-based interventions targeted to MBIs that have their origins in MBSR and which are claimed to have connections to "Buddhist principles" of practice. They also include mindfulness-based mind fitness training (MMFT), which is a recent adaptation of MBSR for delivering pre-deployment mindfulness programs to military personnel.

The first component is described as "contemplative practices that are spiritual and/or religious" and as serving to "center us, bring us away from mental dispersal, and connect us with our immediate experience." Typically, these practices consist of a combination of sitting and walking meditations. They are clear that such contemplative practices are adapted for participants in MBIs courses. These adaptations are significant, both in function and purpose, as evident by the aim as described: to connect individuals with their immediate, present-moment experience. Describing the meditative practice of MBIs as a means of "centering" and reducing "mental dispersal," appears to be equivalent to reducing mental ruminations about the past and future in order to enhance the connection with immediate experience. Viewed as a therapeutic modality for sensory enhancement, contemplative practice is construed as focusing on everyday activities to cultivate a mode of attentiveness for dealing with the stresses and anxieties of ordinary life (Purser 2014).

Perhaps the signature example of this mode of mindfulness-as-sensory enhancement is the mindful eating of a raisin, the first MBSR exercise introduced in the beginning of an eight-week program. The mindful of eating the raisin brings the immediacy of experience back to life; the participant comes to know and appreciate the raisin in a different way by focusing attention on the sensations of eating it. This mode of contemplative practice focuses on the epistemological aspect of meditation. The self-as-knower engages in a meditative practice that results in a sensory enhancement of the immediacy of experience and which, in no doubt, has therapeutic benefits.

Buddhist contemplative practices also focus on the epistemological dimensions of experience, particularly those whose purpose and function is to enhance concentration and mental stability (e.g., śamatha, calm abiding). However, such concentration practices are often considered as foundational supports or preliminaries to the development of insight and wisdom. The practice of insight meditation, along with other related practices whose purpose are the development of wisdom, or prajñ $\bar{a}$, are aimed to effect a fundamental ontological shift in being and radical transformation of the self, or the one who knows. The outcome is not merely therapeutic in nature (sensory enhancement in the service of individual well-being or stress reduction) but the emergence of a radical transformation in one's vision of reality coupled with a spontaneous moral engagement with the world.

However, there is another epistemological aspect of Buddhist philosophy (and by implication Buddhist meditative practices), which has to do with a fundamental error of perception. This perceptual error is often referred to as "basic or fundamental ignorance," but such a translation falls short in explicating the innate and reflexive perceptual process that is 
also considered the root cause of dukkha (and for now, this term will not be rendered or translated as "suffering," which will become more apparent later). Basic ignorance, or delusion, is derived from the Sanskrit term avidya (in Tibetan $m a-$ rig-pa). The antonym is vidya, which is often translated as "seeing." However, in this context, it refers to the perceptual capacity for clearly seeing the true nature of reality and things as they are (this includes subjects and objects), that is, as impermanent, interdependent and lacking any intrinsic reality (Garfield 2015, p. 26).

According to Buddhist philosophy, it is this fundamental misperception that is at the root of dukkha, which is quite at odds with the explanation given by Monteiro et al. (2015). Their second component claims to draw on Buddhist philosophy by explaining that the root of suffering is due to mental dispersal and dysfunctional stances to the experiences of anger, clinging and confusion. It is also unclear what they really mean when they state that suffering is the result of a failure to utilize perceptual skills effectively and constructively. Further clarification is needed to parse this notion of dukkha as being derivative of a fundamental error of perception, and as being caused by a perceptual process. First, the perceptual process within the broad context of Buddhist philosophy is not to be thought of as simply a set of perceptual or cognitive skills that can be applied more or less effectively. Rather, the perceptual process being spoken of here is deeply primal, innate, and embedded in our cognitive reflexes (Garfield 2015). Garfield (2015, p. 28) provides further clarification, as he stated:

"Dukkha, however, is caused by a perceptual process. It is not that we engage with the world, or contemplate ourselves, and infer or decide that we or the things around us are permanent, independent and have identifiable intrinsic natures. Rather, we take the world and ourselves to be like that in our immediate perceptual engagement. Perception itself is therefore shot through with reification."

As Garfield made clear, the perceptual process is tainted and distorted by the superimposition of reification; a process that is not in the conscious domain of a cognitive skill or even philosophical analysis. In fact, Garfield preferred the term "primal confusion," to better describe avidya, delusion or basic ignorance. The Buddhist path culminating in the development of wisdom is aimed to dispel primal confusion by developing and cultivating the power of insight to uproot the innate and latent tendencies that infiltrates the perceptual processes leading to the reification of both self and objects. Thus, the cessation of dukkha requires a thoroughgoing reorientation, facilitated by the orchestrated synergies of the entire Noble Eightfold Pathaimed at the deepest strata of ontology in order to effect a fundamental transformation in epistemology. In contrast, according to Monteiro et al. (2015), the reduction of suffering, allegedly through Buddhist-based concepts, amounts to the cultivation of "experiential awareness" (isn't all awareness experiential?), but such concepts, they went on to add, are not at all unique to Buddhism - they are also operative in such psychotherapeutic approaches as Gendlin's focusing therapy, which also trains clients to be attentive to their bodily felt sensations.

It should be apparent by now why it is so important to clarify exactly what is meant by "Buddhist philosophy" in order to understand both the commonalities as well as the major points of departure between contemporary and traditional mindfulness. Moreover, because the term "Buddhism" is a modern invention of European orientalists, and is far from being monolithic, making sweeping claims to "Buddhist philosophy" without contextualizing such claims is fraught with perils. The tendency to date has been towards a cross-cultural conflation and an uncritical transposition of Buddhist terms, principles and concepts from the religious domain into clinical and therapeutic contexts. This is problematic as many Buddhist terms have a wide semantic range and their intended meaning, role and function can only be understood within their respective religious and historical contexts, which means taking into account their embeddedness within a soteriology and systematic path oriented towards liberation and awakening.

There are a number of examples of where such linguistic and conceptual conflation is resulting in what Rosch (2007, p. 259) referred to as a "confusion of levels." For example, Dorjee (2010) made an important distinction regarding the role of mindfulness as a precursor to, and as a separate mental faculty from, the development of wisdom and insight. She distinguished the therapeutic mechanisms of MBSR, such as "decentering" and deautomatization of mental events, from the higher stages of the meta-awareness of mind that are developed during the fourth foundation of mindfulness as practiced within Theravada Buddhist tradition. In this latter stage of advanced mindfulness training, well after the attention has been stabilized and refined (samädhi), there is often a pronounced dissolution of the subtle sense of "I, me or mine" and a deep insight into nature of the codependent origination (Dorjee 2010; Olendzki 2010. Similarly, such advanced levels of mind-training can be found in the Tibetan Buddhist tradition, which culminates in the arising of wisdom and pristine awareness (rigpa) (Wallace 2012). This dimension of the mind is radiant, luminous and clear, and transcends the six modes of consciousness (the five physical senses and the ordinary mental consciousness). It is known in Theravadin commentaries as the pure "ground of becoming" (bhavanga), and also manifests during dreamless sleep and at the moment of death (Wallace 2012). In the Tibetan tradition, this experience of non-dual awareness is no longer even viewed as "mindfulness." 
When words and phrases such as "insight," "wisdom," "witnessing," "dukkha" "seeing things as they are," and "direct perception" are lifted out of a Buddhist context and reused in Western therapeutic mindfulness discourse, their meanings change significantly. Perhaps the most conflated term and overused phrase in usage in a therapeutic mindfulness context is "insight" and "seeing things as they really are." Dorjee (2010) pointed out that within the therapeutic mindfulness context, "insight" is more descriptive of the decentered perspective on our thoughts and feelings, or what Wallace and Shapiro (2006) referred to as "reperceiving." This signifies taking a more detached stance in relation to one's thoughts and feelings. This is a very different level of insight as compared with how the term is used within the Theravada tradition, which, as alluded to earlier, is more descriptive of a penetrating insight into the three characteristics of impermanence (annica), not-self (anattā), and all conditioned phenomena as suffering ( $d u k k h a)$, accompanied by "a complete dissolution of an independent self" (Dorjee 2010). Both Dorjee (2010) and Rosch (2007) also called attention to how the decentered perspective that is developed in MBSR (an eight week program) is often conflated and confused with some of the most advanced meditative states in the Buddhist traditions, including Dzogchen. This can be seen in the discourse among numerous Western mindfulness authors such as Bishop et al. (2004), Brown et al. (2007), Kabat-Zinn (2011), and Teasdale et al. (2002) who are fond of the phrase "seeing things as they really are." However, in a Buddhist context, this refers to the penetrating insight into the three characteristics and a complete dissolution of the "observer-observed" dichotomy. In a clinical and contemporary mindfulness context it is spoken of in a more generalized and therapeutic sense, describing a basic recognition and ability to detach from the contents of mental events. Rosch (2007, p. 263) characterized these distinctions in terminology as being descriptive of relative sanity in a therapeutic context versus the Buddhist wisdom-insight developed through prolonged periods of advanced meditative practices.

This trend towards linguistic conflation extends to the meditative practice domain, in which case, traditional Buddhist practices are refashioned, modified or completely changed to such an extent that they bear little similarity to their original function and purpose. What remains is a reductionistic form of Crypto-Buddhism. For example, MBSR utilizes the "body scan" which is proclaimed to be based on the first foundation of mindfulness practice, as found in the Satipațthana sutta (Discourse on the Foundation of Mindfulness). Cullen (2011) made the claims "Perhaps it is important to reiterate here that MBSR is informed by and grounded in the application of the four foundations of mindfulness and the view that mindfulness, as taught in this program, has elements of all of the brahma vihäras seamlessly integrated into it." The qualifier here is, of course, the ambiguous notion of what it really means to be "informed by" and "grounded" in Buddhist meditative practices. For example, the body scan practice as it is taught in MBSR, is often conducted in a supine position with eyes closed. The basic instructions given are to begin noticing sensations, starting with the feet, and moving progressively through the limbs, torso, and ending at the top of the head. In her ethnographic study of MBSR classes, Rosch (2014) found that participants described this session as a form of relaxation, with many reporting that the practice was used as an aid to facilitate the onset of sleep. Many of the participants also said that it helped them to sleep or actually put them to sleep, some reporting happily that they had never stayed awake for the entire CD. Rosch (2014, p. 13) also observed, that during the group MBSR sessions, "a chorus of snores typically accompanied the body scan."

Compare this account of the body scan with the traditional 32-part body scan practice in the Satipațthāna Sutta which systematically reviews and contemplates the anatomical constitution of the body as a means to reduce one's attachment to the body. Contemplation of the body instructions are oriented to seeing its impurities, even directing attention to contemplating bodily orifices, feces, guts, pus and so on - and other more repulsive features, all with the aim to induce a realization that there is nothing inherently beautiful or attractive about the nature of the body, in order to counter the tendency towards conceit (Anālayo 2010, p. 148). Even the monk Mahayasi Sayadaw, a twentieth century Theravada reformer, instructed his students to dwell upon the impurities of the body in order to develop an aversion to it.

Additional practices in the contemplation of the body include mindfulness visualizations of a decaying corpse thrown aside in a charnel ground, being eaten and devoured by various creatures, such as crows, hawks, vultures, wormsprogressively decaying until even the skeleton bones turn to dust. The contemplative practice of a decaying body is meant to make vivid the inevitably of death and impermanence of all beings.

It appears that the body scan as practiced in MBSR is a recontextualization of the modernist adaptation of Burmese Buddhist meditation teacher Ledi Sayadaw and Indian teacher S.N. Goenka's variation on scanning body sensations. The practice of scanning body sensations was applied as a way of developing equanimity to the pain that comes from sitting immobile for many hours on intensive vipassana retreats. In this context, participants were taught to view sensations as being transient vibrations, thereby hopefully eliminating all desire and aversion from their minds (Rosch 2014).

The body scan in MBSR does not instruct participants to view sensations as "transient vibrations" in order to endure painful sensations while remaining vigilant, alert and immobile in a sitting posture, nor to develop a detachment to the body, nor does it encourage participants to see the inevitability 
of the body's death and its inherent unattractiveness. Instead, the body scan in MBSR is guided by therapeutic aims: the practical benefits derived from relaxation can result in "selfacceptance" and "healing."

Monteiro et al. (2015) accused the traditional mindfulness communities as not greeting nor positively welcoming the exponential number of clinical and scientific studies investigating the efficacies and mechanisms of MBIs. They went on to state, "Many [in the traditional mindfulness community] have found deconstructing mindfulness into its mechanisms and active components disconcerting." Alan Wallace is specifically targeted as being representative of these "disconcerting" sentiments, given his critical questioning of the metaphysics of scientific materialism in the field of contemplative neuroscience, "which, in his view, is inconsistent with the teachings of the Buddha." What really appears disconcerting here - and essentially a non-sequitur - is conflating investigative studies into the underlying mechanisms and active neural components of mindfulness with a metaphysical critique of scientific materialism. It also seems quite odd to single out Alan Wallace as holding an anti-scientific position given his instrumental role in forging the early dialogues between scientists and the Dalai Lama at the Mind and Life Institute, as well as his pioneering scientific research on the Shamatha project in collaboration with numerous neuroscientists. Monteiro et al. went on attempting to persuade that there is ample and conclusive evidence for the clinical efficacy of MBIs based on a single meta-analytic study they cite (Eberth and Sedlmeier 2012). What is not mentioned here are the numerous methodological issues with MBI studies, such as the wide variance with how mindfulness across various studies is conceptualized, variations in program design, small sample sizes, inadequate controls of confounding factors, a lack of randomized control trials and active control groups, a lack of long-term follow-up data and longitudinal studies of MBI participants, an overreliance on questionable self-report measures, wide variations in teacher experience and competence, and poor monitoring of participant adherence to practice protocols (Shonin et al. 2013).

Monteiro et al. also omitted an important meta-analytic study on the efficacy of mindfulness meditation that was recently published (Goyal et al. 2014). Goyal et al. reviewed 18,753 citations of meditation studies and found only 47 of them to have active control groups. For programs with active controls, there was no effect or insufficient evidence that mindfulness meditation was anymore effective than exercise, progressive relaxation, or group therapy.

Perhaps the "disconcerting" sentiment in the traditional mindfulness communities has more to do with the hype and overblown conclusions regarding the scientific evidence associated with MBIs. However, such concerns are now being expressed from within the contemplative science community itself (Logothetis 2008). In fact, the Mind \& Life Institute recently convened a working group of neuroscientists and clinical researchers to address strategies for countering the hype and evaluating the validity of media reports on scientific studies of mindfulness (Kerr 2014). According to Britton, "public enthusiasm is outpacing scientific evidence," noting that most MBI studies which lack active control groups are being passed along as scientific evidence, often by those who stand to benefit from mindfulness programs (Heuman 2014a, p. 1). Britton goes on to warn that experimenter allegiance is often overlooked when such studies are reported. When the researcher also happens to be a creator of a clinical mindfulness program it can, according to Britton, "count for a larger effect than the treatment itself" (Heuman 2014a).

\section{Two Streams, Two Intentions}

Monteiro et al. maintained that contemporary and traditional mindfulness share a singular and common intention "to alleviate suffering in the world as it is now," implying that these two streams share the same roots. Such is not the case. There is common ground, but only on the surface. The goals and aims of contemporary and traditional mindfulness diverge; the former is concerned with the alleviation of worldly suffering and the practical benefits derived from mindfulness practice. Traditional mindfulness (embedded within the Buddhist Eightfold Path) is concerned with the cessation of dukkha and, depending on the specific tradition and context, culminates in the fruition of awakening and the attainment of nirvana. The telos of contemporary mindfulness is therapeutic in nature. Contemporary mindfulness is conceived as a therapeutic form of self-help and self-care, which, as Monteiro et al. (2015, p. 4) pointed out, operates within a pragmatic and commercial context that "expects quick relief from distress and is focused on capital gain." Buddhist, or traditional mindfulness, operates within a soteriological context or path (marga) that creates a commonality of concern which informs all the various strands of its religious endeavor - moral values, ritual observances, doctrinal teachings, and contemplative exercises - into a unified network of practices focused on liberation (Buswell and Gimello 1994). Rather than being motivated by "quick relief from distress and capital gain," some Buddhist traditions consider the path of liberation as evolving over many lifetimes, involving deeper levels of renunciation from worldly life.

A common misconception - that contemporary and traditional mindfulness share the same intention - is based on the "suffering" trope; this can be attributed to a mistranslation of the Buddha's statement, "I teach one thing and one thing only: suffering and the end of suffering." However, as Bhikkhu Bodhi (2013) has pointed out, the correct translation is, "In the past, monks, and also now, I teach suffering and the cessation of suffering." Moreover, Bhikkhu Bodhi has also 
clarified that any utterance of the Buddha was always guided by the intention to enhance the welfare and happiness of those receiving his message. The Buddha's statement regarding the cessation of suffering was made in a particular context, specifically in response to a question someone had asked the Buddha in the hopes that he would engage in metaphysical speculation. Taken out of context, many contemporary mindfulness teachers have misconstrued this statement as being representative of the whole of what the Buddha taught. As Bhikkhu Bodhi (2013) has pointed out, the Buddha taught on a wide range of topics besides suffering and its cessation, including important topics like the workings of karma, moral and ethical behaviors and dependent co-origination, as well as many practical topics for householders, such as marriage, the distribution of wealth, and household budgets. Summarizing this misconception, Bhikkhu Bodhi (2013) stated: “....But his words are not always tied to the theme of 'suffering and its cessation.' To insist on confining them to this topic is to drastically narrow the range of the dharma."

Contemporary mindfulness teachers also tend to equate dukkha with suffering, as it is a common translation, but this equivalence masks the deeper strata of suffering, for which traditional mindfulness seeks to eradicate (Purser 2014). Contemporary mindfulness is oriented towards the alleviation of mundane and superficial level of $d u k k h a$ - our ordinary physical and mental pain - anxieties, worries, fears, frustrations, headaches, and other chronic physical ailments. There is also the dukkha of change, the fundamental reality that nothing is permanent and that all conditioned phenomena are subject to change. All material objects, all sources of sensual and psychological pleasure, our sense of emotional and physical security, are inherently impermanent and subject to change. Finally, the deepest and most pervasive level of $d u k k h a$, the deepest strata of suffering, is inextricably linked with interdependence - the causal chains that are well beyond are control and agency (Garfield 2015). This is a much more subtle level of suffering, based on the premise that any phenomena that takes form or birth is subject to the laws of karma and dependent origination. Pervasive suffering is rooted in a fundamental delusion, or fixed view, that the existence of a person in a world is a continuous being from the time of birth (until death) (Purser 2014). Dukkha is a much more pervasive and comprehensive in nature than suffering as usually understood, or what we commonly think of as "distress." Rather, $d u k k h a$ is a fundamental structuring of the nature of conditioned existence. Garfield (2015, p. 23) made a useful clarification:

"We can now see why dukkha is so pervasive, and so why the term dukkha does not admit of easy translation into a language that does not encode this view of reality. Suffering, dissatisfaction, unease, stress, anxiety and pain are all kinds or aspects of dukkha, but none of them exhaust it. Siddhartha Gautama's genius was not simply to see that we suffer, or that many of us are unhappy. That has been noted many times by philosophers in many traditions. His genius was instead to see that dukkha is the fundamental structure of our lives, what Heidegger would have called our existentiale. To be human is to live in dukkha."

In describing the current practice of traditional mindfulness, Monteiro et al. (2015) seem to privilege the Annāpānasati and Satipațhāna suttas, the primary instructions for mindfulness training in the Theravada tradition. These suttas have also been the mainstay for Western neo-vipassana insight meditation centers and it is no coincidence that these centers are the most closely aligned with MBSR. However, associating traditional mindfulness to only these two suttas from the Pali Nikayas does not do justice to the wide range of conceptions and practices of mindfulness within the Buddhist tradition. For example, even within the Theravada tradition, there are many other seminal texts and commentarial treatises (such as the Milindapañha, Abhidamma, Visuddhimagga), with each offering nuanced understandings of the moral phenomenology of mindfulness. Beyond this, the Mahayana traditions (such as Chan, Zen, Pure Land) and the Tibetan Vajrayana (Mahamudra, the Tantras, and Dzogchen) each have unique conceptions of mindfulness and its function on different stages of the path. Classic teachings by these later traditions, along with the teachings of such Buddhist adepts as Asanga, Kamalaśîla, and Shantideva have rarely entered the contemporary mindfulness discourse.

Mindfulness-based interventions have been heralded as a veritable paradigm shift, or "third-force," in the field of psychotherapy and behavioral medicine. Monteiro et al. attribute this to the unique stance that mindfulness-based interventions develop, allowing clients to dis-identify with the contents of their experience and to relate differently to their thoughts, feelings, and mental ruminations. One of their examples is that of MBCT and how this intervention fosters such a detached stance. Gilpin (2008) made a very astute observation that while mindfulness-based interventions may encourage the self-as-observer to "be with" experience differently, this may actually reinforce a stronger sense of the agency of the self. Gilpin (2008, p. 243) elaborated on this point, as he stated:

"Rather than encouraging the meditator to see through the illusion of the Self which is 'observing' phenomena, its language implies such a position can be adopted, and by doing so one can enhance one's control of (particularly negative) mental and emotional experiences. At a subtle level, such habitual positioning may actually reinforce one's sense of self such that, if one were to continue practicing beyond a course (as MBCT encourages), the very progress such practices are designed to 
facilitate on the Buddhist path would be blocked by an unrealistic view or assessment of the meditative process." (italics in original).

There are a number of unexamined assumptions that such a therapeutic stance entails. First is the notion that the individual client has full control and agency for their own emotional reactivity, as well as their ability to decenter from the contents of their experience. Lomas et al. (2014), however, have recently challenged this assumption, noting that clients currently suffering from depression may lack the mental strength to engage in the challenging work of decentering from negative cognitions, and that MBCT could potentially exacerbate mental ruminations (see also Teasdale et al. 2003). Second, the assumption that a client has full agency over their cognitions also assumes that they are fully responsible for their own "healing," a popular narrative in the complementary and alternative medicine domain. This philosophy is closely aligned with much of the self-help and pop psychology literature which proselytizes mindfulness can tap into "inner resources" that will facilitate recovery from, or at least acceptance of, an illness - and in some cases, serve as preventive medicine from the onset of stress-related diseases and chronic illnesses (Barker 2008). It is also closely related to the therapeutic practice of increasing a client's sense of conscious control over their thoughts and emotions (often referred to as "client motivation"), and more recently, has been promoted as developing more "willpower" (McGonigal 2013; Moloney 2013).

The policy implications of these claims are also suggestive that a client's misery (along with the full agency and capacity to heal) and mental suffering is simply located inside their head, and therefore mindfulness-based interventions provide the means for enhancing self-regulation, self-management, self-acceptance, and self-control. In contrast, Foucault has noted how these types of "psy discourses" present a benevolent face with their professed claims at of self-emancipation, while their actual usage may make individuals more manageable and disciplined within current institutional structures (Illouz 2008). Payne (2014) has suggested that the contemporary mindfulness community has failed to recognize their highly privatized, atomistic, and neoliberal conceptions of the autonomous self/individual. This cultural bias places a heavy burden on the individual, as the source of suffering is viewed as a lack of self-regulation and entirely self-made. Mindfulness-based interventions are in close resonance with the ideological basis for "blaming the victim," as it is the individual (not the social context, history, or factors such as socio-economic status, inequities) that is held fully responsible for their own emotional reactivity, mental suffering and misery, as well as their own illnesses.

In addition to the fields of psychology and medicine, Monteiro et al. (2015) also claim mindfulness approaches have "given new perspectives to organizational psychology and changing organizational cultures." However, there is not a single empirical study to date in any of the top-tier organizational studies journals that provides convincing evidence that mindfulness-based interventions in organizations have led to substantive and fundamental changes in organizational culture. Even the most visible and publicized corporate mindfulness program at Google, "Search Inside Yourself," for which over 2000 Google employees have taken, has not yielded any publishable or empirical results with regards to corporate culture change. The issue of whether mindfulness-based interventions could have unintended consequences in suppressing or marginalizing critical thought that investigates the very context, structures, and systems of causes that give rise to social suffering will be addressed later in this article.

Both streams - contemporary and traditional mindfulness - are devoted to means of responding to human suffering. For contemporary mindfulness, it is via therapeutic interventions that enhance skills in self-regulation, reducing the proliferation of negative cognitions and mental ruminations. For traditional mindfulness, it is via a comprehensive mental and ethical training system whose soteriological aim is the full path of liberation from the cycle of samsara. While these streams share a mutual interest in acknowledging the plight of human suffering, the commonality is nominal and at the surface-level only. Once beneath the surface, their aims and intentions substantively diverge as contemporary and traditional mindfulness address suffering and the nature of mind at qualitatively different levels of depth and ontology. Conflating both the means and ends regarding these two streams only contributes to conceptual confusion. The claim that contemporary mindfulness retains the "essence of a tradition" was shown earlier to be a strategy of appropriation and radical decontextualization (Wilson 2014, p. 44).

\section{Ethics in Mindfulness: Their Absence or Presence Is Not the (Only) Question}

Monteiro et al. (2015) attempted to represent the Buddhist critique of contemporary mindfulness as stemming from: (1) debates and fundamental differences between religion and science; (2) incompatible conceptual frameworks, and mainly; (3) a decontextualized and secularized form of mindfulness that is void of an ethical foundation. Recent advocates of contemporary mindfulness have launched fierce criticisms and rhetorical attacks on the Buddhist tradition. For example, Sam Harris (2014) exemplified this when he characterized the Buddhist religious tradition as an "accidental strand" of history and tells those in the mindfulness movement that they "no longer need to be in the religion business." Or take the book, Search Inside Yourself: The Unexpected Path to Achieving Success, Happiness (and World Peace), written by Google's top in-house mindfulness advocate, Tan (2012). The 
inside front cover flap immediately signals that the authority for mindfulness certainly "cannot be the domain of bald people in funny robes." Rather it lies with the scientists in white lab-coats, as Tan cited study after study to back up his claims that mindfulness delivers greater happiness, prosperity, health, and career success. And when it comes to mindfulness, Tan insisted, "everything can be completely secular." Dan Harris (2014), co-anchor of ABC's Nightline and Good Morning America, and the author of the best-selling book $10 \%$ Happier, said, "I always thought mindfulness practice was for people who live in yurts, or collect crystals ... as it turns out, there is all this science that says it can boost your immune system, reduce your blood pressure, and rewire key parts of your brain," as he decried "meditation's massive PR problem", code for shedding any associations with anything that smacks of tradition. Sam Harris gave an obligatory nod to tradition, "That's not to say that people who have brought meditation to the West haven't done great and truly heroic things ...but now we are at a new stage. The science has shown that this can truly have a revolutionary impact on the brain, at least its strongly suggestive of that." These are familiar tropes of the contemporary mindfulness movement: that science, in validating mindfulness practice, has liberated it from the flaky, foreign, irrational, outdated and spooky metaphysics of religious tradition.

This rhetoric is troublesome in that it casts the Buddhist tradition as amounting to nothing more than an outdated set of cultural accretions. Such messages betray not only a terrible lack of understanding of the very nature of religion in general and Buddhism in particular, or what it means to engage meaningfully with a tradition, but they also perpetuate a naïve belief in the unassailable authority science and the form of logic derived from it. These views are representative of scientism, a fundamental belief that "scientists alone hold the key to understanding reality, and that key is the range of scientific methods accepted by the orthodox scientific community" (Wallace 2014). Contrary to Monteiro et al.'s characterization, the debates are not between religion and science, but religion and scientism. When contemporary mindfulness advocates marginalize the Buddhist religious tradition, they are essentially defending the beliefs of scientific materialism, dismissing any methods or evidence that is incompatible with this belief system. Why engage in a dialogue with tradition when it is considered, at best, as basically irrelevant, or even as a detriment and anachronistic to the progress of the mindfulness movement? The messaging is that it is of strategic necessity that Buddhism be purged, that all residues of tradition jettisoned, if mindfulness is to be widely propagated as a scientifically approved method immune to cultural and historical influences. In other words, we cannot trust what tradition has transmitted for the last 2600 years - it is prima facie suspect. Only by placing our faith in science can we validate the value of mindfulness.
With regards to the second claim, the issue of incompatible conceptual frameworks, the problem is more than merely one of transporting terminologies from a soteriological to a clinical context. Rather, what is often missed among contemporary mindfulness advocates is a modernistic bias that presupposes that the modern world-view is universal, immune to it own cultural assumptions. Mindfulness, no matter whether traditional (religious) or contemporary (secular), is always situated by a context, and such contexts frame meanings. A strippeddown and decontextualized model of contemporary mindfulness is problematic only because it assumes that mindfulness has an essence free of context, and by extracting that essence it can be better understood, studied and practiced. The mindfulness movement suffers from a massive blind spot because it obviously grows out of a distinctly American context that has prided itself on the narrative of scientific progress, the belief in the individual as the sole nexus of meaning, an entrepreneurial ethos, and other underlying and generally unexamined assumptions that are anything but universal, much less Buddhist, but are simply absorbed from our social environment. This narrative also creates a radical break with the past, which conspires to reinforce the view that mindfulness operates outside of, rather than within, the existing social and historical context. In this respect, the mindfulness revolution is a big bang innovation myth, a uniquely American cultural phenomenon.

Monteiro et al. framed the Buddhist critique as mainly being a matter of the omission of ethics in contemporary and clinical applications of mindfulness, but this formulation misses the heart of the matter. The issue is not whether ethical dimensions of mindfulness are present or absent, implicit or explicit in contemporary mindfulness applications, but a set of assumptions that view ethical frameworks for contextualizing mindfulness practice as an inconvenient "add-on," a set of prescriptions, rules or moral imperatives for behavior and action. Monteiro et al. added to this confusion by presenting the Buddhist ethical concerns as simply being a matter of developing "right" (sammā sati) versus "wrong" mindfulness (miccha sati).

Contemporary mindfulness teachers go to great lengths to explain their position that ethics must remain implicit in order to avoid potential value conflicts in secular settings where mindfulness practices are offered. There are a variety of arguments offered that support this position: the practice of clinical and contemporary mindfulness practices naturally lead to ethical behavior; that ethical dimensions are "builtinto" the practice itself; ethical outcomes depend on the mindfulness teacher "embodying" and modeling ethical behavior, and so on. There appears to be an avoidance of moral inquiry in contemporary mindfulness discourse, along with a general reluctance to consider how the practice of mindfulness and questions of the good are unavoidably intertwined. This is due partially to the fact that the contemporary mindfulness 
movement is operating within a market society, where the dominant ethos is market logic and the value neutral discourse of economics. Thus, there is a powerful appeal to avoid engagement with moral and ethical questions when economistic conceptions of virtue have entered spheres of life that were traditionally buffered from market logic (Sandel 2013). Letting the market decide questions of the good, assuming that ethical behavior will "naturally" arise out of either the practices themselves or via the professionalism and "embodiment" of teachers, or through the happenstance of inductive self-discovery, might be referred to as the "laissez-fare mindfulness" school (Wilson 2014, p. 194).

\section{Disentangling Buddhist Ethics: Moral Engagement and the Problems of Social Suffering}

Like many other contemporary mindfulness teachers, Monteiro et al. are fond of viewing MBIs - whether applied in clinical, corporate, or public sector contexts - as another Buddhist utilization of skillful means or upāya. Monteiro et al. and others, such as Kabat-Zinn, have appropriated this Buddhist concept as a way of retrospectively explaining how their adaptations of mindfulness to modern contexts is "developed in a manner consistent" with Buddhist teachings. Their interpretation of skillful means is that it is equivalent to a pedagogical tool for adapting mindfulness practices to the needs of a secular and cultural context, however, omits a few important details.

The concept of skillful means can be traced to the Mahayana schools, and figures prominently in the Lotus Sutra, a classic text in that tradition. In the Lotus Sutra, numerous parables show the Buddha taking on different forms and deceiving his audiences - purely out of compassion in order to lead them to the final destination of liberation and awakening. Even the Theravada tradition (which Monteiro et al. is suggestive that because of its close adherence to the monastic code of ethics, the vinaya, is a version of Buddhist fundamentalism), also has teaching stories from the sutras that exemplify the Buddha's skillful means. A classic teaching story is Kisa Gotami, who tragically loses her infant son and pleads to the Buddha for him to bring her son back to life. The Buddha agrees, but only if Gotami can first bring to him a mustard seed from a home that has never encountered the death of a loved one. Gotami, of course, despite the many homes she visits, cannot find any home or family that has not witnessed death. She returns herself healed and becomes a nun and disciple of the Buddha.

In all of the examples and allegories, whether in Mahayana or Theravada texts, it is the fully awakened Buddha and highly advanced Bodhisattavas who employ expedient, skillful means to lead their followers to the path of liberation. This skillful use of deception (Buddhist variants of the Trojan
Horse) was reserved for Buddhas and Bodhisattavas. As (Wilson 2014, p. 91) pointed out, when people like KabatZinn and other mindfulness teachers such as Monteiro et al., "draw on the concept of skillful means, they authorize themselves via the example of the Buddha to change aspects of the tradition to better suit the different environmental circumstances of Buddhism outside of its premodern Asian historical context." Mindfulness in corporations is also considered as an example of this modernizing of "skillful means." The skillful Trojan Horse metaphor is often used to defend claims that introducing mindfulness programs into corporations will naturally and eventually lead to a major transformation of corporate behaviors and practices-away from self-interest and narrow concerns for maximizing shareholder profits- to more humanistic, compassionate, and socially responsible organizations that are concerned for the public good. Corporate mindfulness advocates have often compare their initiatives with the work of the Buddha, noting that he often taught kings, merchants, and feudal village leaders. This is true, but misleading. While the Buddha taught the dharma to leaders and the merchant class, what he taught was not a mindfulnessbased intervention so they could simply feel better about themselves, nor did he simply provide them a meditative technique for improving their concentration so that they could obtain even more wealth and riches, rather, the Buddha advocated a wiser form of ethical leadership that counteracted the mental poisons of greed, ill will and delusion.

Monteiro et al. have positioned their assessment of MBIs in terms of the degree to which these methods are in alignment with basic Buddhist principles, which they have circumscribed in terms of right mindfulness, insight into the root causes of suffering, and the inclusion of the ethical components of mindfulness. This is admirable, but also limiting, for their assessment fails to critically examine how MBIs are limited - not because they fall short of emulating Buddhist principles - but because of their adherence to a therapeutic culture and discourse of self-help that is premised on a highly privatized sense of self and neoliberal conceptions of subjectivity that is clinically withdrawn from the public sphere.

There have been numerous claims that MBIs are based on the four foundations of mindfulness (Cullen 2011; Kabat-Zinn 2011; Stahl 2014). What is actually meant by the claim that MBIs are "based on" one of the most highly revered discourse of the Buddha, the Satipattthāna Sutta, remains ambiguous. The four foundations of mindfulness provide exact instructions on the practice of mindfulness meditation (Anālayo 2010). The original, overarching purpose and context of these mindfulness practices were based on the renunciation of greed, desires and discontent with the world, and these instructions in the four foundations were considered as a vehicle for a direct path to liberation (nibanna). The discourse is divided into four sections, pertaining to mindfulness of the body $(k \bar{a} y \bar{a})$, feelings (vedan $\bar{a})$, mind (citta), and mind-objects 
(also called dhammas, or phenomena). Mindfulness of the body (kāyānupassanāa) comprises fourteen subjects of meditation, with mindfulness of the breath (ānapannasati) being the most popular. Mindfulness of feeling (vedanānupāssanā) is of three types, pleasant, painful, and neutral, referring to both material and spiritual feelings. Mindfulness of mind (cittānupassanā) is differentiated into contrasting states of mind, namely, with and without lust, hatred, delusion, a mind contracted or distracted, exalted or unexalted, surpassable or unsurpassable, concentrated or unconcentrated. Finally, mindfulness of mental objects or phenomena (dhammānupassanā) consists of five categories: the five hindrances, the six internal and external senses, the seven factors of enlightenment, and the four noble truths. In addition, the instructions also include contemplations directed towards observing the arising and passing away of these phenomena in the stream of experience.

While MBIs may claim and appear to draw, albeit highly selectively, from the four foundations of mindfulness, their extraction from the context of Buddhist liberation radically alters the nature and meaning of these practices. Mindfulness meditation becomes psychologized and reoriented to improving and enhancing ordinary worldly life - a method for alleviating the stresses, anxieties and worries of middle-class lifestyles. There is, of course, nothing problematic in utilizing Buddhist techniques for therapeutic and clinical purposes, but to claim that MBIs are equivalent secular expressions of the four foundations of mindfulness goes too far. How is it, for example, that MBIs which emphasize "nonjudgmental awareness" engage in the third foundation of mindfulness which entails discriminating unwholesome states of mind to contemplating the presence (or absence) of higher states of mind? How do MBIs provide instructions in the fourth foundation of mindfulness, which includes contemplating the seven factors of awakening and the four noble truths (including the eight fold path)? There is also a strong emphasis in the Satipațthana on both internal and external phenomena, especially in terms of noting their impermanent nature. MBIs, however, tend to be much more internal in focus. There is also very little emphasis or training in contemplating the conditioned and impermanent nature of the five aggregates (material form, feelings, cognition, volitions and consciousness). This perhaps explains why several practices are omitted in MBIs, such as contemplating the body as a decaying corpse, contemplating the inevitability of the death of one's own body, and viewing the body in terms of the four elements (components of the first foundation of mindfulness). As I previously pointed out, the body scan in MBIs only has a distant family resemblance to the 32-body part practice in the Satipatthana. In the latter text, the body parts are visualized and contemplated with a view of seeing them as composite, impermanent and unattractive. The whole aim of this practice is to reduce attachment to the body as well as conceit, not merely to release tension and stress. Granted, those who enroll in 8-week MBI courses are there for relief of chronic pain and stress, not for ultimate religious liberation from the wheel of birth and death, detachment from the body and worldly concerns, and the abandonment of craving.

Perhaps the most dubious claim among MBI advocates is that ethics are implicit, and need to remain so, in both the practice and in the teaching of mindfulness in secular settings. Monteiro et al. turned to a single study by Shapiro, Jazaieri and Goldin (2012) to justify their claim that implicit ethics, as exemplified in MBSR, leads to an increase in ethical decision making and moral reasoning. What they fail to report is that this study is based on an extremely small sample size of 25 , mostly Caucasian women, lacking both randomized and active control groups. Furthermore, the study relied completely on self-report data using the Mindfulness Attention Awareness Scale (MAAS) and the Five-Facet Mindfulness Questionnaire (FFMQ), both of which have been the subject of severe criticisms in the clinical literature (Grossman and Van Dam 2011).

The debate on whether ethics are implicit in mindfulness practice itself, or whether ethics should remain implicit in the teaching of secular mindfulness, is partly driven by a fundamental misconception that the ethical aspects of Buddhist mindfulness practice and its path of spiritual-moral development are derived from adherence to prescriptive behaviors and ethical imperatives, or the intentions of a self-as-agent. In other words, Monteiro et al., Kabat-Zinn, and others in the MBI community view ethics and morality through a Western Judeo-Christian lens, equating them to a set of abstract principles to which one can be compelled to ascend. The usual reservation raised by MBI teachers is that there is no room for allowing ethics or moral discourse into secular mindfulness programs as it could potentially be seen as an imposition of religious dogma or pose value conflicts - is premised on this Western view of ethics. Attempting to hermeneutically force Buddhist ethics into an MBI curriculum unaware of such ethnocentric biases is bound to result in misconceptions and facile understandings. Monteiro et al. proposed a confusing admixture of virtue ethics, a distorted conception of Mahayana Buddhist ethics as utilitarianism, deontological claims to universality via a misreading of Gethin, and a strained attempt to convert traditional Buddhist teachings into secular counterparts (the Four Noble Truths now become the cultivation of "moral courage"). Keown (2001), whom Monteiro et al. cite throughout this section, warned against the subtle danger of "cultural misappropriation" in attempts to selectively import Buddhist morality into Westernized views. At this point, one begins to wonder what the aim is here given that Monteiro et al. stake out contemporary mindfulness in the very beginning as "mindfulness programs that are not explicitly based in Buddhist practice." Even (McCown 2013, p. 65), who is cited as an advocate for MBIs, seems wary of importing Buddhist ethics into contemporary mindfulness practice as he states, 
"To articulate an ethic based on distinctly Buddhist concepts or uses specifically Buddhist language, then, would run counter to the concepts and practices that have, in smaller or larger part, fueled the growth of MBIs."

Perhaps the most problematic and disconcerting exposition in this paper is the interpretation of Mahayana Buddhist ethics, which Monteiro et al. use as an example to justify and rationalize killing, as well as a supposed means to go beyond the seemingly narrow edicts of the Theravada school. Monteiro et al. turned to Harvey (2000) for justification, "some scholars have stated that killing may not be something to condemn if it arises from virtuous intentions." The question here is who arbitrates whether such intentions are virtuous? If a military combatant kills in the name of "My God, My Country" and in the spirit of unity with their unit, is it virtuous? Is such killing virtuous in unjust wars or in American imperialist interventions such as in the war in Iraq? Are drone operators trained in mindfulness exempt from all moral accountability because their intentions are simply to defend our "national interests"? This is evidently no problem for Monteiro et al. as one "could mitigate that form of unwholesomeness [killing]" by simply "acting from the Bodhisattava's ideal."

Monterio et al. have resorted to what I call the perverse "Mahayana exceptionalism" argument, a convenient spiritual loophole that can easily be misused to rationalize and defend militarism and police brutality. This sort of mental gymnastics in appropriating the Mahayana for dubious ends is not without historical precedent. Victoria's (2006) classic work, Zen at War, documents how Mahayana Buddhist teachings were distorted and misinterpreted to justify the Japanese Imperialism, modern Japanese militarism and the many atrocities inflicted on millions of Russian, Chinese and Korean civilians. Consider how D.T. Suzuki also utilized the justification of virtuous intentions to rationalize killing as an act of spontaneous compassion:

"The sword is generally associated with killing, and most of us wonder how it can come into connection with Zen, which is a school of Buddhism teaching the gospel of love and mercy. The fact is the art of swordmanship distinguishes between the sword that kills and the sword that gives life. The one that is used by a technician cannot go any further than killing, for he never appeals to the sword unless he intends to kill. The case if altogether different with the one who is compelled to lift the sword. For it is really not he but the sword itself that does the killing. He had no desire to do harm to anybody, but the enemy appears and makes himself a victim. It is as though the sword performs automatically its function of justice, which is the function of mercy.... When the sword is expected to play this sort of role in human life, it is no more a weapon of self- defense or an instrument of killing, and the swordsman turns into an artist of the first grade, engaged in producing a work of genuine originality" (quoted in Victoria 2006, p. 110).

Monteiro et al. are basically dredging doctrinal support for war and violence through an overly simplistic use of the skillful means (upāya) teaching. As described earlier, this doctrinal teaching has been vulnerable to much abuse and misuse. The classic teaching story illustrative of skillful means in the Mahayana is to be found in the Upāyakauśalyasütra, which describes an incident when the Buddha Shakyamuni was still a bodhisattva in one of his past lives. In this story, Shakyamuni was on a ship and became aware of a robber on board who had the intention of killing all the passengers on the ship. To prevent this act from happening, Shakyamuni decides to kill the robber out of compassion-saving not only the passengers, but also the robber from accruing even greater negative karma. Because the Buddha Shakyamuni acted out of great compassion, because his intention was wholesome, his act was morally justified. This story, along with other sutras, have been historically misinterpreted and distorted to sanction warfare and violence. What is omitted and glossed over by those who distort these teachings is that it is a highly advanced Bodhisattva or even a Buddha that is engaging in these acts, not Japanese kamikaze pilots emboldened by Imperial Zen propaganda or by 18 -year-old privates in the US Marines engaging in mindfulness practice for twelve minutes a day as they do in mindfulness-based mind fitness training (MMFT). Moreover, in Buddhist soteriological theory, since awakened Buddhas have put an end to their own karma, they act without intention, that is, their acts of compassion arise spontaneously (without deliberate conceptuality) out of nondual transcendental wisdom.

Attempting to find moral justification via an appeal to the Mahayana for killing, even if such acts are driven by positive intentions within morally ambiguous situations, is fraught with peril. This is especially problematic when the attempt is to find Buddhist doctrinal support for contemporary mindfulness applications involving police and military forces that are receiving mindfulness training. It is quite dangerous to simply assume that police and military forces are engaged in right mindfulness, or are uniquely and heroically acting as awakened Bodhisattavas, carefully discerning and "weighing the ultimate cost of shooting or not shooting" prior to making the decision to kill the targeted person. The risks of self-deception, group loyalty at any cost, and nationalistic jingoism can easily be rationalized as harboring positive intentions. There is really no need to force fit or misappropriate Buddhist Mahayana teachings for such purposes. Of course, there are indeed exceptional and extreme cases, such that not taking a life or not retaliating would lead to even greater tragic losses, such as in the instance of Hitler's expansionism of Nazi Germany, or 
in a case where a police officer must shoot to prevent a lunatic gunman from killing innocent children at a school site. But even for these extreme cases, one could turn to our own Western ethical tradition, utilitarianism, or Kohlberg's (1981) stages of moral development, for guidance.

Perhaps the main confusion in the Monteiro et al. paper as it pertains to Buddhist ethics, and its possible import to contemporary mindfulness, is that it is ultimately not a clean moral theory of action. Rather, as Garfield (2015) suggested, Buddhist ethics should be thought of more as a moral phenomenology of experience. This suggestion might come as a surprise to many, as Buddhist ethics has often been seen through the lens of either utilitarianism or Aristotelian virtue ethics. What is frequently, if not perhaps always overlooked among contemporary mindfulness teachers, is that Buddhist ethics is situated within a complex nexus of thoroughgoing interdependence, dependent origination (pratiyasamutpada). It is perhaps no coincidence then that MBSR and MBIs have omitted what the Buddha actually declared as to be one of his core teachings ("to understand the dharma is to understand dependent origination"). Garfield (2015) was adamant that Buddhist moral phenomenology is concerned with locating human action within a vast causal nexus of interdependence, and of karma, that "Moral reflection on action must take all of these dimensions of dependence into account. To focus merely on motivation, or on character, or on the action itself, or on its consequences for others, would be to ignore much that is important" (Garfield 2015, p. 313).

Contemporary mindfulness proponents are operating from a faulty premise, at least from a Buddhist moral theory point of view, that ethics are somehow separable from the nature of experience and from meditative practices themselves - in other words, because ethics are still viewed as a set of imperatives or consequentialist calculus for deciphering "virtuous intentions" and their relation to action - they miss the essential point. Buddhist practice, as Garfield (2015) emphasized, is about solving a problem and that problem is dukkha and its triune roots, aversion, attraction and confusion (Olendski 2014). The Buddhist eightfold noble path is a solution to the problem of $d u k k h a$, and simply focusing on motivation and intention as the arbiter of ethical action is to take an extremely narrow view. Again, Garfield (2015, p. 315) cautioned us against superimposing Western ethical biases on Buddhist moral theory: "The eightfold path identifies not a set of rights or duties, nor a set of virtues, but a set of areas of concern or dimensions of conduct. The path indicates the complexity of human moral life and the complexity of the sources of suffering." This also points to the fact that any ethical orientation to mindfulness must be situated within a larger social context; ethical action only has meaning and sense when it pertains to how actions affect and impact the lives of others in the vast causal nexus of interdependence.
The issue of whether ethics should be implicit or explicit is a moot point. There is no way of avoiding a moral point of view, as ethical engagement is predicated on our perceptual process. Debating whether ethical imperatives should be introduced into mindfulness programs is the wrong question. When ethical engagement is viewed in terms of a reordering of our perceptual process, rather than on "embodying virtuous intentions," deciphering actions, rights, duties and prescriptions, or virtues - we can begin to think of mindfulness in terms of whether it cultivates, what Garfield has termed "morally awakened perception" (Garfield 2015, p. 325). However, this is only half of the equation. What is often missed in contemporary mindfulness is that elevating ethical concerns in mindfulness curricula, practices, and community discourse raises the stakes to act and care for the suffering of others. Such a project means moving beyond the therapeutic to activism. Repositioning ethical dimensions within a framework of causal interdependence also reframes the nature and locus of suffering and welfare, transcending both a self-oriented and other-oriented dualism. This is the innovative contribution of the Mahayana, and the bodhisattva ideal, that genuine wellbeing is always grounded in an ethic of care and action on behalf of all sentient beings, near or far.

Perhaps a good example of how contemporary mindfulness is ethically challenged is in its recent application in corporate settings. However, it is not that recent if we look again to Japan and how the militarization of Zen took on a different form after World War II. After the war, there was great interest among Japanese corporations to reinstill and return to "the old virtues of obedience and conformity" and "selfless devotion to one's assigned duties" (Victoria 2006, p. 182). This was the beginning of what was known as the Corporate Zen boom, and it continues to be a popular training program whereby select managers and employees spend time in Zen monasteries, indoctrinated into the values and behaviors of selfless devotion to one's superiors. Sakai Tokugen, a leading Zen master who has been involved in Corporate Zen training programs, describes the value of such training industrial warriors:

"Sincerity [in carrying out orders] means having feelings and actions of absolute service, giving one's all [to the task at hand]. In doing this there can be no thought of personal loss or gain.....By carrying out our [assigned] tasks, we become part of the life of the entire universe; we realize our original True Self.....This is the most noble thing a human can do" (quoted in Victoria 2006, p. 185).

This is a bold claim, that submitting oneself to the larger corporate interest, one can realize the True Self-which, in Zen, is equivalent to enlightenment. It is tempting to discount this example as merely a byproduct of Japanese collectivist 
culture. Yet, this example illustrates how a secular adaptation of traditional Zen Buddhism, along with its use of samädhi power (focused concentration and attention enhancement), has been coopted for bolstering obedience, conformity and loyalty to corporate authority.

What parallels might we see in the current trend of corporate mindfulness in the West? Wall Street traders and hedge fund managers speak of the benefits of mindfulness training in terms of how it is helping to "fine-tune their brains," or as a means for "upping their game," and "giving them an edge" (Burton and Effinger 2014). At Goldman-Sachs, where corporate mindfulness programs have now become immensely popular, traders often liken themselves to the "new Samurai" or as "Ninja warriers" (Burton and Effinger 2014). Monteiro et al. listed numerous benefits of corporate mindfulness programs - better listening, seeking common ground, and learning to navigate the dialect of the organization (citing Bush and Goleman 2013). In other words, mindfulness in the workplace is promoted as a way to reduce friction, increase efficiency, and relieve the pressures of late-capitalism. They go on to claim, "In workplace programs, concepts such as being comfortable with uncertainty, taking a nonjudgmental stance to a situation, or cultivating compassionate action are intended to transform emotional reactivity so that the situation can be met with skillful means" (p. 11). In all of these examples, the scope of the mindfulness training is focused on the individual employee.

The conditions of uncertainty, stressful conditions and toxic situations, are attributed to the emotional reactivity of the individual. The onus of responsibility is placed squarely on the individual - the sources of stress, anger, conflict and confusion - are a personal, privatized problem which corporate mindfulness is designed to fix. It isn't a misperception "that mindfulness programs intend to develop an indiscriminate tolerance for stress,", as they put it, but the fact that corporate mindfulness programs have excluded inquiry into the systemic sources of stress in the organization. Stress in organizations cannot merely be attributed to an individual's emotional reactivity and lack of self-regulation; it is also systemic, cultural and institutional in scope. Restricting the scope of mindfulness intervention to the level of the individual in corporate settings amounts to blaming the victim.

Huffington (2014), an avid promoter of mindfulness in the workplace proposed a "third metric" of success-well-being, wisdom, and wonder (the first two metrics, of course, are money and power). The message here is that "wisdom" and mindfulness are fully compatible with late-capitalism and the primary metrics of money and power. Social critics, such as (Zizek 2001, p. 1), contended that the Western Buddhist (and by extension, the corporate mindfulness) "meditative stance is arguably the most efficient way for us to fully participate in capitalist dynamics while retaining the appearance of mental sanity." The jury is still out on whether corporate mindfulness programs will remain limited to a palliative for helping employees cope and tolerate the conditions of corporate capitalism, reinforcing rather than challenging the status quo.

Many promoters of corporate mindfulness claim that offering mindfulness programs to individuals, even if limited to personal stress reduction, works insidiously from within, and will eventually lead to wiser, more compassionate and socially responsible corporations (Boyce 2014; Halliwell 2014; Hunter 2013; Maturano 2014; Tan 2012). Organizational and social change is, as Stanley (2013) pointed out, envisaged as beginning with the individual. Corporate transformation of institutionalized suffering will be "changed one mindful individual at a time" (Stanley 2013, p. 8). This is, again, the mindfulness is a "Trojan Horse" argument. The notion that corporate transformation is effected through the power of empowering individuals with mindfulness training resembles in some respects the "experiments" and dubious claims by Transcendental Meditation (TM) aspirants that groups of TM practitioners meditating together could lower crime rates in a large metropolitan city. Boyce (2014, p. 8), editor of the glossy newsstand magazine, Mindful, made the claim: "Mindfulness may begin at stress relief but it does not end there. It naturally leads to inquisitiveness about our own minds and examination of how we are connected to other people, of the causes and effects of our actions.... Who knows what a leader...might do for the greater good with the aid of a little mindfulness?"

That is a good question, who knows? Monteiro et al. themselves acknowledged that it is probably naïve to expect that corporate mindfulness training programs that focus on individuals will lead to any sort of significant change in corporate culture. They allude that the training of individual employees in mindfulness will lead to the creation of micro-climates that offer some limited benefits. At best, corporate mindfulness programs have succeeded in creating what Healy (2013) referred to as "integrity bubbles," myopic islands and privatized glimpses of stress reduction and enhanced focused attention while mindlessly externalizing macro-tensions and structural inequalities. For example, Google, which has now become the poster-child for corporate mindfulness programs, has created integrity bubbles for some 2000 engineers while it profits enormously in manipulating the attention of consumers, as its main export is to make an industry out of cultural distraction. There appears to be no attention given in the Search Inside Yourself mindfulness curriculum for being mindful of, or cultivating wise attention to call into question the long list of Google's nefarious corporate practices such as privacy violations, off-shore tax evasion, their grueling 80-hour work weeks, or their negative impact on housing evictions in San Francisco (Ream 2014). Or take Monsanto, once idolized for its early adoption of corporate mindfulness programs, but notorious for its egregious ethics violations, negligence of public health, abuse of patent laws, and production of 
potentially risky genetically modified organisms (GMOs), along with their lobbying efforts to defeat consumer protections. General Mills, another company that has received media attention for its large-scale corporate mindfulness program (Gelles 2012), has collaborated with Monsanto in lobbying against the consumer rights groups which are demanding the full disclosure of the content of Cheerios, one of their signature cereals that is marketed to children.

What all of these examples call forth is whether corporate mindfulness programs are the "Trojan Horse" and "disruptive technology" (Hunter 2013) that they claim to be, or whether such media publicity amounts to a form of "saffron washing" (Fiet 2014)? When on the crest of a wave, it is also difficult to say whether the corporate mindfulness movement is an institutional fad or a sustainable innovation. Only time will tell. Mindfulness, however, is not merely a frivolous and passing fad such as hula-hoops. The enthusiasm for mindfulness programs is having a contagion effect, now endorsed and promoted by physicians, psychotherapists, educators, corporate CEOs, politicians, and top military brass - requiring significant institutional investments - and erroneously assuming, as Cathy Kerr worries, that its "suitable for all people in all circumstances" (Heuman 2014b). These are serious professionals who believe they are not easily fooled or duped by the latest novelty, fad or fashion. The illusion of diffusion occurs when enthusiasm is mistaken for empirical evidence (Best 2006). However, as Best (2006, p. 18) pointed out, the illusion of diffusion plays a key role in institutional fads, as serious people have a strong conviction "that far from being a fad, this innovation represents progress - it is an improvement that is worthwhile and will endure."

\section{Conclusions}

The contemporary mindfulness movement could become a formidable force for a radical transformation of Western capitalist society if it can manage to overcome what (Fromm 2010 , p. 15) called the "pathology of normalcy." Fromm's social critique of psychotherapy and psychiatry of his day was aimed at how the notion that mental health in society complacently had become a matter of individual adjustment to the status quo of a society that was itself off kilter. For Fromm, the "normal" functioning of society could itself be a disturbing pattern of collective pathology. Krishnamurti (1966) once remarked, "It is no measure of health to be well-adjusted to a profoundly sick society." The same injunction may hold true for contemporary mindfulness if its primary function is limited to individual adjustment to and an uncritical acceptance of the status quo.

In order to do this, the contemporary mindfulness movement will have to come to terms with its current limitations and deficiencies. First, it should dispense with the rhetoric that the essence of the dharma is encapsulated in a single practice divorced from a wider cultural and historical context. This includes the development of more other-oriented and relational forms of meditative practice that aim to cultivate prosocial behaviors. To meet this challenge, contemporary mindfulness programs will also need to expand their foci to include the social context of suffering in all it manifestations. This omission has been due to the rapid psychologization of mindfulness and it merger with the self-help industry under the aegis of therapeutic discourse. A major fall-out of this psychologized conception of mindfulness is that it comes to be understood at best — as a path for personal salvation, and at worst, as just another self-help technique - both of which are blind and insensitive to the social, political and economic dimensions of suffering. Such discourse has deemphasized social relations and has covertly depoliticized socio-economic problems, localizing the causes of distress and unhappiness as being strictly internal and within the individual (Moloney 2013). Rather than serving as a social lubricant for the smooth functioning of society, contemporary mindfulness programs can begin to encourage critical thought and investigation into the wider social and political causes of social suffering. In other words, rather than concealing socially induced forms of suffering as exclusively problems of "emotional self-regulation," "reactivity," "self-acceptance," and "self-management," mindfulness programs can assist people in diagnosing the mentally toxic aspects of their social contexts.

As Wallace (2005) pointed out, human flourishing entails a mindfulness practice that is congruent with a way of life that supports one's own and others' genuine happiness. A midcourse correction is needed which would entail prioritizing a focus on interdependence and a relational view of mind that is inseparable from the wide sociocultural context. An othercentered "civic mindfulness," (Healy 2013) can expand the realm of practice towards a relational perspective that is discerning of social dukkha, developing corporate mindfulness program curricula that examine the causes of institutionalized greed, ill will, and delusion (Loy 2003).

Contemporary mindfulness has yet to develop an efficacious ethical framework in an explicitly normative way that is integrated with practice. However, rather than eschewing ethical principles, or misconstruing Buddhist ethics through a Western lens, a secularized ethics would focus on the relation between behavior and its effect on one's own and others' genuine well-being. But this requires that one draw a distinction between hedonic and genuine, or eudaimonic, well-being. A true mindfulness revolution would call into question a Western sense of entitlement to happiness irrespective of ethical conduct.

Finally, the contemporary mindfulness movement is in dire need of becoming more communal, fostering ways individuals can forge mutually supportive bonds with a sense of shared purpose and continuity over time. Communal well- 
being is a prerequisite for authentic happiness, and a sustainable path towards even this secular end is unlikely to take root if mindfulness is reduced to a form of "mental fitness" conducted in isolation. The heart of mindfulness is a collective practice, that which unites people towards acting for the common good, which in turn provides the basis for human flourishing and social transformation.

\section{References}

Anālayo. (2010). Satipathāna: The direct path to realization. Birmingham: Windhorse Publications.

Barker, M. (2008). Self-healing in late-modernity: The case of mindfulness. (unpublished paper).

Bazzano, M. (2013). In praise of stress induction: Mindfulness revisited. European Journal of Psychotherapy and Counselling, 15(2), 174185.

Beauchamp, T. (2010). Autonomy and consent. In F. Miller \& A. Weetheimer (Eds.), The ethics of consent: Theory and practice. New York: Oxford University Press.

Bellah, R. (1985). Habits of the heart. Berkeley, CA: University of California Press.

Best, J. (2006). Flavor of the month: Why smart people fall for fads. Berkeley, CA: University of California Press.

Bishop, S. R., Lau, M., Shapiro, S., Carlson, L., Anderson, N. D., Carmody, J., et al. (2004). Mindfulness: A proposed operational definition. Clinical Psychology: Science and Practice, 11(3), 230 241.

Bodhi, B. (2011). What does mindfulness really mean? A canonical perspective. Contemporary Buddhism, 12(1), 19-39.

Bodhi, B. (2013). What the Buddha never said: I teach only suffering and the end of suffering. Tricycle, Winter. Retrieved http://www.tricycle. $\mathrm{com} /$ what-buddha-never-said/i-teach-only-suffering-and-endsuffering.

Bodhi, B. (2014a). Fusion of horizons. (unpublished paper).

Bodhi, B. (2014b). Personal communication.

Bodhi, B. (2014c). Personal communication.

Boyce, B. (2014). It's not McMindfulness. Mindful December, p.8

Braun, E. (2013). The birth of insight. Chicago, IL: University of Chicago Press.

Brazier, D. (2013). Mindfulness reconsidered. European Journal of Psychotherapy and Counselling, 15(2), 116-126.

Brown, C. G. (2013). The healing gods: Complementary and alternative medicine in Christian America. New York: Oxford University Press.

Brown, K. W., Ryan, R. M., \& Creswell, J. D. (2007). Mindfulness: Theoretical foundations and evidence for its salutary effects. Psychological Inquiry, 18(4), 211-237.

Burton, K., \& Effinger, A. (2014). To make a killing on Wall Street, start meditating. Retrieved from Bloomberg, 27 May 2014, http://www. bloomberg.com/news/2014-05-28/to-make-killing-on-wall-streetstart-meditating.html.

Bush, M., \& Goleman, D. (2013). Working with mindfulness: Research and practice of mindfulness techniques with organizations. Kindleebook Amazon.com.

Buswell, R. E., \& Gimello, R. M. (1994). The path to liberation: The marga and its transformations in Buddhist thought. New Delhi: Motilal Bararsidass.

Buswell, R., \& Lopez, D. (2014). 10 Misconceptions about Buddhism. Tricycle. Retrieved from http://www.tricycle.com/blog/10misconceptions-about-buddhism.

Center for Mindfulness (2014). Retrieved from http://www.umassmed. $\mathrm{edu} / \mathrm{cfm} / \mathrm{stress}-$ reduction/history-of-mbsr/.
Cohen, E. (2010). From the Bodhi tree, to the analyst's couch, then into the MRI scanner: The psychologisation of Buddhism. Annual Review of Critical Psychology, 8, 97-119.

Coseru, C. (2014). Mindfulness, mind science, clinical science, Buddhism... Where are we now? Facebook group. June 52014 Retrieved from https://www.facebook.com/groups/429677260502964/.

Cullen, M. (2011). Mindfulness-based interventions: An emerging phenomenon. Mindfulness, 2, 186-193.

Davis, J. (2004). Strong roots. Barre, MA: Dhamma Dana Pubishing Barre Center.

Dorjee, D. (2010). Kinds and dimensions of mindfulness: Why it important to distinguishing them. Mindfulness, 1(3), 152-160.

Eberth \& Sedlmeier. (2012). The effects of mindfulness meditation: A meta-analysis. Mindfulness, 3, 174-189.

Fiet, S. (2014). Mindfulness the Google way: Well-intention saffromwashing? Retrieved from http://www.nadalila.org/mindfulness-thegoogle-way-well-intentioned-saffron-washing/.

Fromm, E. (2010). The pathology of normalcy. New York: American Mental Health Foundation Books.

Garfield, J. (2015). Engaging Buddhism: Why it matters to philosophy. New York: Oxford University Press.

Gelles, D. (2012). The mind business, from http://www.ft.com/cms/s/2/ d9cb7940-ebea-11e1-985a-00144feab49a.html\#axzz2MuOcUpfA.

Gethin, R. (2001). The Buddhist path to awakening: A study of the BodhiPakkhiya Dhamma (previously published in 1992). Oxford: Oneworld Publications.

Gilpin, R. (2008). Theravada Buddhism and mindfulness-based cognitive therapy. Contemporary Buddhism, 9(2), 227-251.

Goldstein, E. (2013). Beyond McMindfulness: A thoughtful reply. Huffington Post, 7/12/2013. http://blogs.psychcentral.com/ mindfulness/2013/07/beyond-momindfulness-throwing-the-babyout-with-the-bathwater/.

Goyal, M., Singh, S., Sibinga, E. M. S., Gould, N. F., Rowland-Seymore, A., Sharma, R., et al. (2014). Meditation programs for psychological stress and well-being: A systematic review and meta-analysis. JAMA Internal Medicine, 174(3), 357-368.

Grossman, P., \& Van Dam, N. T. (2011). Mindfulness, by any other name...: trials and tribulations of sati in western psychology and science. Contemporary Buddhism, 12(1), 219-239.

Halliwell, E. (2014). Mindfulness: Has it been hijeacked by business or can it change lives? Retrieved from The Guardian, 25 July 2014 http://www.theguardian.com/sustainable-business/mindfulnesshijacked-business-parliamentary-inquiry.

Halliwell, E. (2011). You don't need the 'right' kind of zafu to be a Buddhist. Retrieved from The Guardian,6 January 2011,http:// www.theguardian.com/commentisfree/belief/2011/jan/06/westernbuddhists-zafu-meditative-method.

Harris, D. (2014a). $10 \%$ happier. New York: It Books.

Harris, S. (2014). Mindfulness is powerful, but keep religion out of it. Retrieved from http://www.samharris.org/.

Harvey, P. (2000). An introduction to Buddhist ethics. Cambridge: Cambridge University Press.

Healy, K. (2013). Searching for integrity: The politics of mindfulness in the digital age. Nomos Journal, August 5, 2013. http:// nomosjournal.org/2013/08/searching-for-integrity/.

Heuman, L. (2014a). Meditation nation. Tricycle, April 25, 2015. Retrieved from http://www.tricycle.com/blog/meditation-nation.

Heuman, L. (2014b). Don't believe the hype. Tricycle, October 01, 2014. Retrieved from http://www.tricycle.com/blog/don\%E2\%80\%99tbelieve-hype.

Huffington, A. (2014). Thrive: The third metric to redefining success and creating a life of well-being, wisdom, and wonder. New York: Harmony Books.

Hunter, J. (2013). Is mindfulness good for buisness. Mindful, April, 52-59.

Illouz, E. (2008). Saving the modern soul: Therapy, emotions, and the culture of self-help. Berekely, CA: University of California Press. 
Ivy, M. (2005). Modernity. In D. S. Lopez (Ed.), Critical terms for the study of Buddhism. Chicago, IL: The University of Chicago Press.

Kabat-Zinn, J. (2011). Some reflections on the origins of MBSR, skillful means, and the trouble with maps. Contemporary Buddhism, 12(01), 281-306.

Kabat-Zinn, J. (2013). Retrieved from the New York Academy of Sciences https://www.youtube.com/watch? $\mathrm{v}=\mathrm{c} 0 \mathrm{dup}-0 \mathrm{Dh} 0 \mathrm{~g}$.

Keown, D. (2001). The nature of Buddhist ethics. New York: Palgrave.

Kerr, C. (2014). Why do studies of meditation and of the brain matter? Retrieved from The Huffington Post, 20 October 2014, http://www. huffingtonpost.com/catherine-kerr/why-do-studies-of-meditat_b_ 6075664.html.

Kohlberg, L. (1981). Essays on moral development, Vol. 1: The philosophy of moral development. San Francisco, CA: Harper \& Row.

Krishnamurti, J. (1966). The collected works of J. Krishnamurti: 19661967: Volume 17: Perennial questions. Seattle, WA: Kindle Edition, Amazon Digital Services.

Langri, T.J. (2013). Mindfulness in cultural context. Retrieved from Advanced Studies Institute lectures on https://www.youtube.com/ watch? $\mathrm{v}=6 \mathrm{PR} 83 \mathrm{yMoGZs}$.

Logothetis, N. K. (2008). What we can do and what we cannot do with fMRI. Nature, 453, 869-878.

Lomas, T., Cartwright, T., Edington, T., Ridge, D. (2014). A qualitative analysis of experiential challenges associated with meditation. Mindfulness. Retrieved from Springer Link http:// link.springer.com/article/10.1007/s12671-014-0329-8.

Lopez, D. (2012). The scientific Buddha. New Haven, CT: Yale University Press.

Loy, D. (2003). The great awakening: A Buddhist social theory. Somerville, MA: Wisdom Publications.

Maturano, J. (2014). Finding the space to lead: A practical guide to mindful leadership. New York: Bloomsbury Press.

McCown, D. (2013). The ethical space of mindfulness in clinical practice. London: Jessica Kingsley Publishers.

McGonigal, K. (2013). The willpower instinct. New York: Avery Trade.

McMahan, D. (2008). The making of Buddhist modernism. New York: Oxford University Press.

Moloney, P. (2013). The therapy industry: The irresistible rise of the talking cure, and why it doesn't work. London: Pluto Press.

Monteiro, L. M., Musten, R. F., \& Compton, J. (2015). Traditional and contemporary mindfulness: Finding the middle path in the tangle of concerns. Mindfulness, 6, 1-13.

Nicklebine, M. (2013). From both sides: Secular Buddhism and the "McMindfulness" question. The Secular Buddhist Association. August 2, 2013. Retrieved from http://secularbuddhism.org/2013/ 08/12/from-both-sides-secular-buddhism-and-the-mcmindfulnessquestion/.

North, A. (2014). The mindfulness backlash. Retrieved from The New York Times, June 30, 2014 http://op-talk.blogs.nytimes.com/2014/ 06/30/the-mindfulness-backlash/? $\mathrm{r}=0$.

Olendski, A. (2014). The mindfulness wedge. Tricycle, Fall, Retrieved from http://www.tricycle.com/thus-have-i-heard/mindfulness-wedge.

Olendzki, A. (2010). Unlimiting mind: The radically experiential psychology of Buddhism. Somerville, MA: Wisdom Publications.

Payne, R. (2014). Corporatist spirituality. Retrieved from https://rkpayne. wordpress.com/2014/02/18/corporatist-spirituality/.

Purser, R. (2014). The myth of the present moment. Mindfulness, Retreived from http://download.springer.com/static/pdf/548/art\% 253 A $10.1007 \% 252$ Fs $12671-014-0333-z . p d f ?$ auth $66=$ 1416427673 5de7e2d80e58dc6ce81fabdcb4c0d3cf\&ext=.pdf.

Purser, R., \& Loy, D. (2013). Beyond McMindfulness. Huffington Post. Retrieved from http://www.huffigtonpost.com/ron-purser/beyondmomindfulness_b 35919289.html.

Ream, A. (2014). Why I disrupted the Wisdom 2.0 conference. Tricycle blog, Retrieved from http://www.tricycle.com/blog/why-idisrupted-wisdom-20-conference.
Roca, T. (2014). The dark night of the soul. Retrieved from The Atlantic, June 25, 2014 http://www.theatlantic.com/health/archive/2014/06/ the-dark-knight-of-the-souls/372766/.

Rosch, E. (2007). More than mindfulness: When you have a tiger by the tail, let it eat you. Psychological Inquiry, 18, 258-263.

Rosch, E. (2014). The emperor's clothes: A look behind the Western mindfulness mystique. In B. Ostafin, M. Robinson, \& B. Meier (Eds.), Handbook of mindfulness and self-regulation. Amsterdam, NL: Springer.

Samuel, G. (2014). Between Buddhism and science, between mind and body. Religion, 5, 560-579.

Sandel, M. (2013). What money can't buy. New York: Farrar, Straus and Giroux.

Schedneck, C. (2013). The decontextualization of Asian religious practices in the context of globalization (unpublished paper). Chianmai University, Thailand

Segal, S. (2013). In defense of mindfulness. Retrieved from The Existential Buddhist blog http://www.existentialbuddhist.com/ 2013/12/in-defense-of-mindfulness/.

Shapiro, S. L., Jazaieri, H., \& Goldin, P. R. (2012). Mindfulness-based stress reduction effects on moral reasoning and decision making. Journal of Positive Psychology, 7(6), 504-515.

Sharf, R. (2013). Mindfulness or Mindlessness: Traditional and Modern Buddhist Critiques of "Bare Awareness. Video lecture Advanced Studies Institute lectures on Mindfulness in a Cultural Context, McGill University. Retrieved from https://blogs.mcgill.ca/tcpsych/ tag/robert-h-sharf/

Shonin, E., Van Gordon, W., \& Griffiths, M. D. (2013). Mindfulnessbased interventions: Towards mindful clinical integration. Frontiers in Psychology, 4, 1-4.

Stahl, B. (2014). Buddhism's alignment with mindfulness. The Secular Buddhist, Episode 204, July 19, 2014.

Stanley, S. (2013). 'Things said or done long ago are recalled and remembered': The ethics of mindfulness in early Buddhism, psychotherapy and clinical psychology. European Journal of Psychotherapy and Counselling, 15(2), 151-162.

Stewart, E. C., \& Bennett, M. J. (1991). American cultural patterns: A cross-cultural perspective. Boston, MA: Intercultural Press.

Tan, C.-M. (2012). Search inside yourself: The unexpected path to achieving success, happiness (and world peace). New York, NY: HarperOne.

Teasdale, J. D., Moore, R. G., Hayhurst, H., Pope, M., Williams, S., \& Segal, Z. V. (2002). Metacognitive awareness and prevention of relapse in depression: empirical evidence. Journal of Consulting and Clinical Psychology, 70(2), 275-282.

Teasdale, J. D., Segal, Z. V., \& Williams, J. M. G. (2003). How does cognitive therapy prevent depressive relapse and why should attentional control (mindfulness) training help? Behavioral Research and Therapy, 33, 25-39.

Thānissaro, B. (2012). Right mindfulness: Memory \& ardency on the Buddhist path. Retrieved from http://www.accesstoinsight.org/lib/ authors/thanissaro/rightmindfulness.pdf.

Thompson, N. (2014). The mindfulness wars. Dangerous Harvests, February 21, 2014 Retrieved from http://dangerousharvests. blogspot.com/2014/02/the-mindfulness-wars.html.

Victoria, B. D. (2006). Zen at war (2nd ed.). Oxford: Rowman \& Littlefield.

Wallace, A. B. (2005). Genuine happiness: Meditation as a path to fulfillment. New York: John Wiley.

Wallace, B.A. (2007). A mindful balance: What did the Buddha really mean by 'mindfulness'? http://buddhanet.net/budas/ebud/ebdha344. htm.

Wallace, B. A. (2012). Meditations of a Buddhist skeptic: A manifesto for the mind sciences and conteplative practice. New York: Columbia University Press.

Wallace, B.A. (2014). Creationism and scientism: One mindset, two belief systems. (unpublished paper). 
Wallace, A., \& Shapiro, S. (2006). Mental balance and well being: Building bridges between Buddhism and Western Psychology. American Psychologist, 61(7), 690-701.

Whitaker, J. (2013). 2013 as the year of mindfulness: Critics and defenders. December 21, 2013. Retrieved from http:// secularbuddhism.org/2013/08/12/from-both-sides-secularbuddhism-and-the-momindfulness-question/.

Wilden. (1980). Systems and structure: Essays in communications and exchange. London: Tavistock Publications.
Williams, J. M. G., \& Kabat-Zinn, J. (2011). Mindfulness: Diverse perspectives on its meaning, origins, and multiple applications at the intersection of science and dharma. Contemporary Buddhism, 12(1), 1-18.

Wilson, J. (2014). Mindful America: The mutual transformation of Buddhist meditation and American culture. New York: Oxford University Press.

Zizek, S. (2001). From Western Marxism to Western Buddhism. Cabinet Magazine Retrieved from http://www.cabinetmagazine.org/issues/ 2/western.php. 